\title{
Load-deflection behaviour of thin-walled plates with a single bolt in shearing
}

\author{
Y.C. He, Y.C. Wang* \\ School of Mechanical, Aerospace and Civil Engineering, University of Manchester, United Kingdom
}

\section{A R T I C L E I N F O}

\section{Article history:}

Received 28 March 2011

Accepted 18 May 2011

Available online 24 June 2011

\section{Keywords:}

Shear connection

Plate

Ductility

Bearing

Analytical method

\begin{abstract}
A B S T R A C T
This paper presents an experimental, numerical and analytical study of the behaviour of thin-walled plates connected by a single bolt under shear. Eighteen tests were carried out to provide detailed data of load-deflection and load-strain curves for validation of the finite element simulation model. The validated finite element model was then used to perform a comprehensive set of parametric studies to investigate the effects of different design parameters on the connected plate behaviour, including initial stiffness, ultimate resistance and maximum deformation at the ultimate resistance. It was found that the stiffness and ultimate resistance could be predicted accurately by using existing methods. The analytical study therefore focused on developing a method to calculate the maximum plate deformation (hole elongation) at the ultimate resistance. Based on the parametric study results, methods of calculating the ultimate deformation were proposed, based on different failure modes of the connection.
\end{abstract}

(c) 2011 Elsevier Ltd. All rights reserved.

\section{Introduction}

Cold-formed thin-walled steel has been used in many areas of civil engineering construction. In cold-formed thin-walled steel structures, bolted connection is often used. Currently, design codes for coldformed thin-walled steel structures (e.g. EN 1993-1-3) may be used to obtain stiffness and load carrying capacity of connections. However, there is no method to evaluate the complete loaddeflection curve, in particular, the deformation capacity of connections. The current status is acceptable if the designer is only interested in structural strength under normal condition or the loading condition in the structure does not change. However, when a structure is under accidental loading such as fire, the load carrying mechanism may change or the loading condition in the structure may change.

For example, in sandwich panel construction, catenary action may be activated to enable partially damaged structure to sustain the applied load [1]. The ability of a structure to develop catenary action depends on the tensile capacity and deformation capacity of the connection [2]. Also, when a beam-column structural connection is exposed to fire, forces in the connection vary throughout the fire exposure. Knowing only the load carrying capacity of the connection components is no longer adequate and it is necessary to have detailed load-deformation behaviour of the components to quantify connection behaviour.

\footnotetext{
* Corresponding author: Tel.: +441613068968.

E-mail address: yong.wang@manchester.ac.uk (Y.C. Wang).
}

The objective of this research is to develop an analytical method to quantify the complete load-deflection behaviour of bolted thin-walled steel plates in bolt shear, illustrated in Fig. 1. This paper will deal with one single bolt, but the resulting loaddeflection behaviour will be able to be used in the so-called component based method [3] to deal with multiple bolts. In the component based method, a connection is split into many single individual components which are treated as springs with specified load-deflection behaviour. These "springs" are then connected in series or parallel ways to represent the connection. The component based method combines flexibility and simplicity and is now firmly established as the preferred method of analyzing hot-rolled connection behaviour and is included in EN 1993-1-8 [3].

Despite bolted connector being ubiquitous in thin-walled connections, a review of past research studies by the authors revealed very limited information on the load-deflection characteristics of this component. Rogers and Hancock $[4,13]$ conducted a series of thin-walled steel connection tests to develop a method to calculate bolted connection bearing failure loads for thin-walled G550 \& G300 steel sheet connection; Rex and Easterling [5] focused on the initial stiffness of the bearing component; Kim and Kuwamura [6] developed a FE model to simulate the bearing behaviour of thin-walled stainless steel bolted connections, focusing on the failure loads under different failure modes without providing information on displacement quantification.

Because of this lack of load-deflection behaviour, the authors conducted a series of 18 tests to obtain experimental results to allow the authors to validate their numerical models. The validated numerical model will then be used to conduct an extensive 


\section{Nomenclature}

$A_{n} \quad$ net cross-section area

$d \quad$ bolt-hole diameter

$e_{1} \quad$ end distance

$e_{2} \quad$ edge distance

$k \quad$ initial stiffness
$F_{t} \quad$ net-section failure load

$F_{S} \quad$ end pull-out failure load

$F_{b, R d} \quad$ bearing failure load

$f_{u} \quad$ ultimate tensile stress

$p_{1} \quad$ spacing of bolt-rows in load transfer direction

$t \quad$ plate thickness parametric study to develop a component behaviour database from which an analytical method can be derived to predict the complete load-deflection behaviour. This paper will present the experimental results, validation of the finite element modelling using the commercial software ABAQUS [7] and parametric study results, and the development and validation of an analytical model.

\section{Test arrangement}

In total, 18 tests were conducted and Table 1 lists the main parameters of these tests. These tests used $1.5 \mathrm{~mm}$ thick plates and $12 \mathrm{~mm}$ bolts with $14 \mathrm{~mm}$ bolt-holes. The tests were designed to investigate the effects of different end/edge distance combinations and their effects on failure modes. Tensile coupon tests were carried out according to BS EN 10002-1:2001 [8]. Fig. 1 shows the experimental set-up with indication of the locations of displacement and strain measurement. The displacement transducer was attached on the plate to track the movement of the bolt head due to bolt-hole elongation. Two thick plates were placed on two sides of the thinwalled steel plate to prevent curling. Fig. 2 shows a test in progress.

\section{Validation of finite element modelling}

The commercial software Abaqus was used to simulate the tests. This section describes the main points of the simulation and compares the simulation and test results.

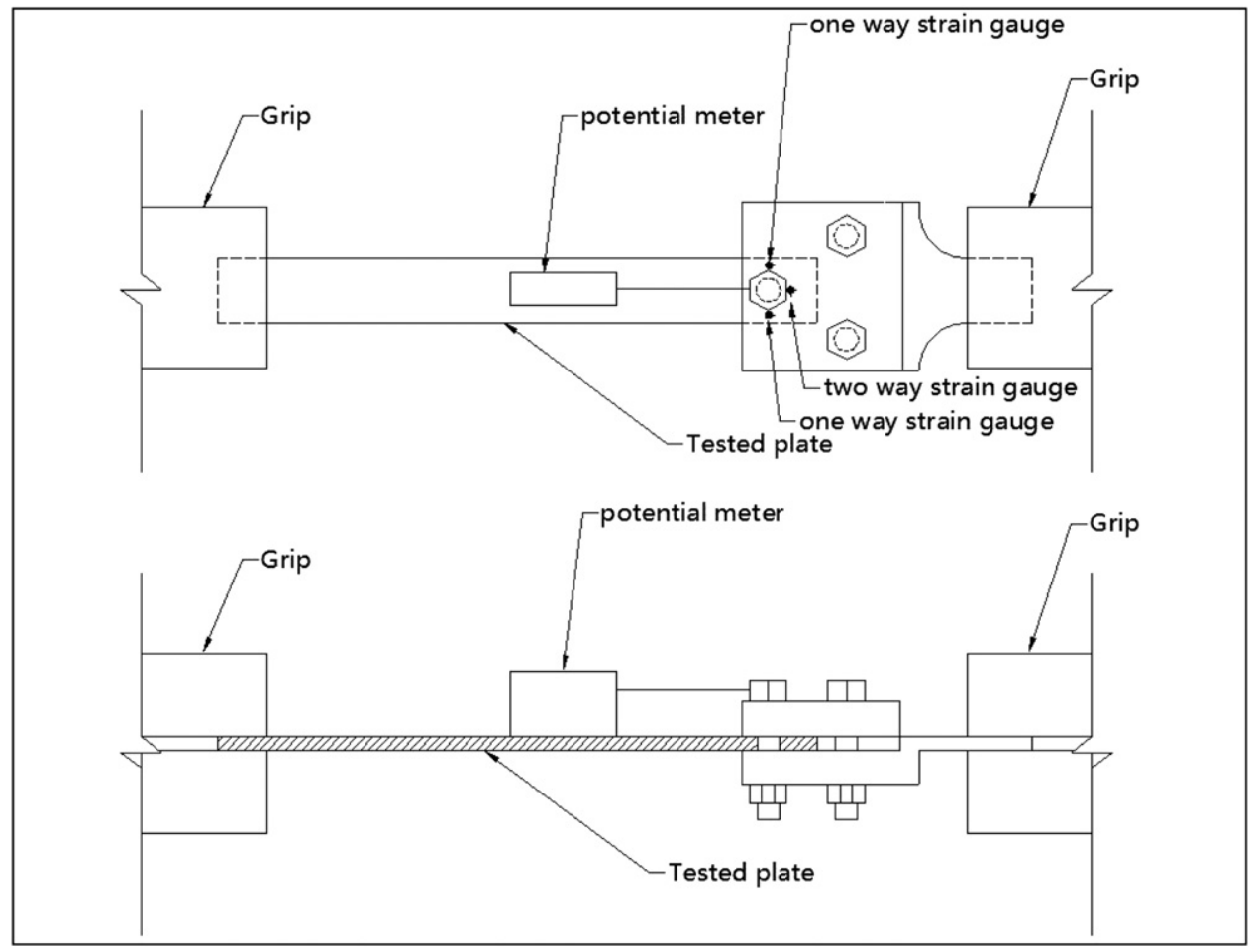

Fig. 1. Bolted connection test set-up.

Table 1

Main parameters of tests.

\begin{tabular}{|c|c|c|c|c|c|}
\hline Test ID & $\begin{array}{l}\text { Number of } \\
\text { replicate tests }\end{array}$ & $\begin{array}{l}\text { Bolt diameter } \\
(\mathrm{mm})\end{array}$ & $\begin{array}{l}\text { Bolt hole diameter } d \\
(\mathrm{~mm})\end{array}$ & $\begin{array}{l}\text { End distance } \\
(\mathrm{mm})\end{array}$ & $\begin{array}{l}\text { Edge distance } \\
(\mathrm{mm})\end{array}$ \\
\hline D14-14-28 & 3 & 12 & 14 & $14(1 d)$ & $14(1 d)$ \\
\hline D14-21-42 & 3 & 12 & 14 & $21(1.5 d)$ & $21(1.5 d)$ \\
\hline D14-20-80 & 3 & 12 & 14 & $20(1.43 d)$ & $40(2.86 d)$ \\
\hline D14-28-80 & 3 & 12 & 14 & $28(2 d)$ & $40(2.86 d)$ \\
\hline D14-70-40 & 3 & 12 & 14 & $70(5 d)$ & $20(1.43 d)$ \\
\hline D14-70-80 & 3 & 12 & 14 & $70(5 d)$ & $40(2.86 d)$ \\
\hline
\end{tabular}




\subsection{Material properties}

It should be noted that the data attained from tensile coupon tests are engineering stress and strain. They should be transferred into true stress and true strain according to the following formulas:

$\sigma_{t}=\sigma_{n}\left(1+\varepsilon_{t}\right)$

$\varepsilon_{t}=\ln \left(1+\varepsilon_{n}\right)$

\subsection{Element types and mesh size}

The ABAQUS simulation model used C3D8R element, which is a three-dimensional, reduced integration solid hexahedral brick element with 8 integration nodes. This element is suitable to be used in both linear and non-linear analysis at large strain and deformation. The reduced integration gives good control on hourglass effect and reduces calculation time. Using brick elements gives detailed information on failure mode, failure load, strain and stress results.

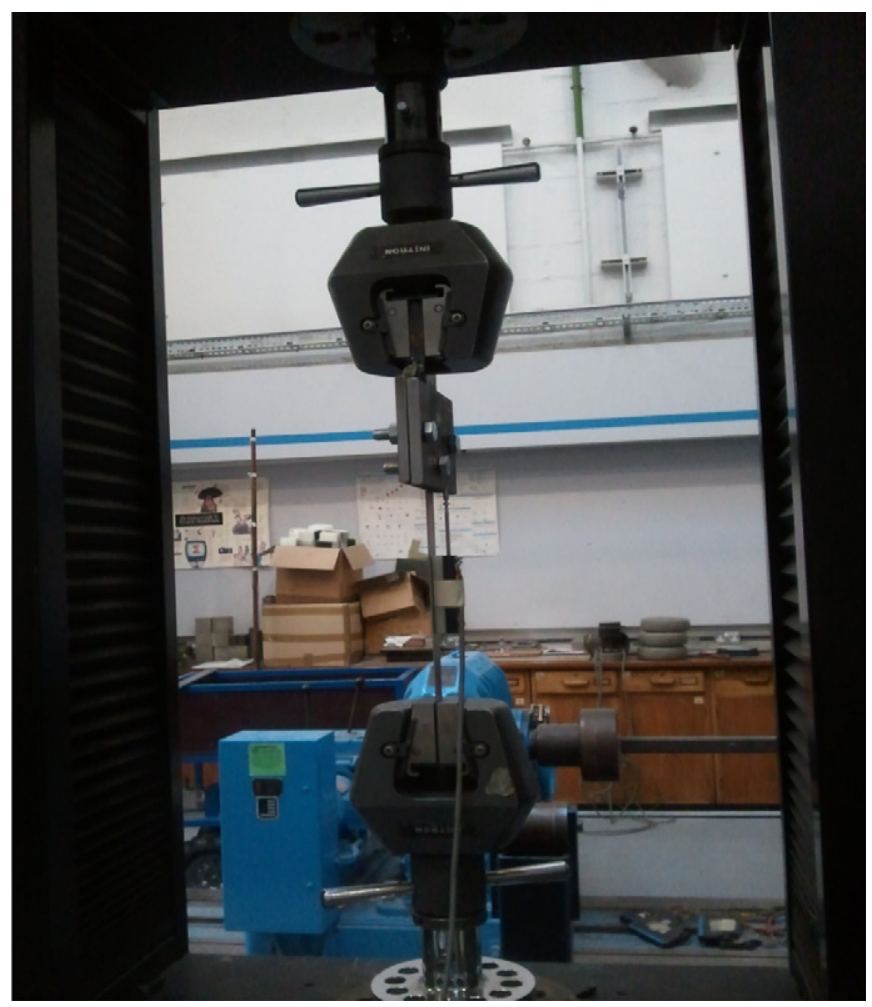

Fig. 2. A test in progress.
A mesh sensitivity study was carried out to determine the best mesh size. Mesh size of $\frac{1}{4}$ plate thickness was found to be sufficient and was applied to places in the structure where a fine mesh was required, i.e. the area around the bolt-hole. For example, Table 2 compares the simulation results using different mesh sizes for one of the tests by Kim and Kuwamura [6] and one of the authors' own tests, using different mesh sizes. The difference in connection failure load is very small, less than 2\%. Fig. 3 shows a typical finite element mesh used.

\subsection{Geometric simplification}

The tested thin-walled steel plate was much more flexible and weaker than the bolt used. In fact, in all tests the bolt showed no visible deformation after the tested plate failed. Therefore, in the simplification, the bolt was modelled using rigid hollow shell elements which did not deform during the entire simulation. This considerably reduced the element number in simulation models and simulation time.

\subsection{Comparison between simulation and test results}

Three duplicate tests were conducted for each arrangement. All three tests were similar so only the mean results are used in this paper. Table 3 compares the recorded and simulated plate failure loads. Fig. 4 compares the observed and simulated failure modes. Fig. 5 compares the recorded and simulated plate loaddeflection relationships. The plate deflection was the bolt hole elongation. Fig. 6 presents a selection of recorded and simulated load-strain results.

The results in Table 3, Figs. 4 and 5 confirm that the finite element model was able to accurately predict the failure mode, failure load and load-deformation curves of all the tests.

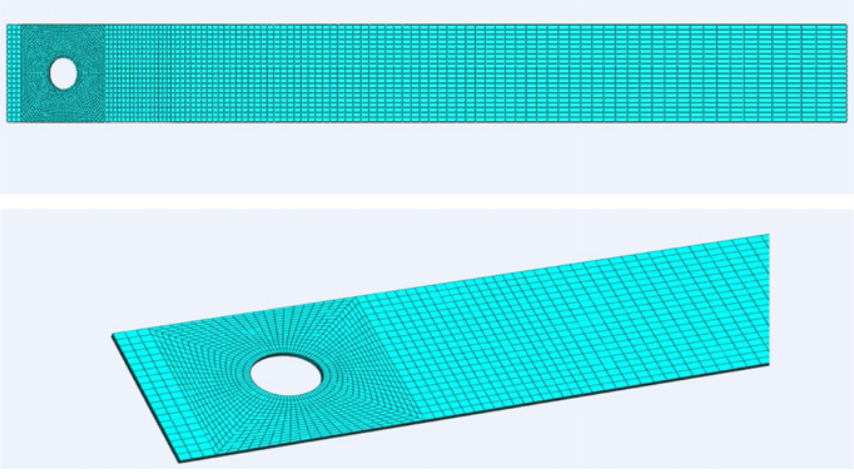

Fig. 3. Typical mesh for plate.

Table 2

Results of mesh sensitivity study.

\begin{tabular}{|c|c|c|c|c|c|c|}
\hline Finite element size (width*length ) & No. of elements & $\begin{array}{l}\text { Increase in mesh } \\
\text { size (\%) }\end{array}$ & Simulation time (s) & $\begin{array}{l}\text { Test strength } \\
P_{e}(\mathrm{KN})\end{array}$ & $\begin{array}{l}\text { Simulation strength } \\
P_{S}(\mathrm{KN})\end{array}$ & $P_{s} / P_{e}$ \\
\hline \multicolumn{7}{|l|}{ Test SB2-4 of Ref. [6] } \\
\hline$t / 2 * t / 2$ & 7188 & 0 & 1603 & 85.62 & 92.17 & 1.077 \\
\hline$t / 3 * t / 3$ & 15,015 & 109 & 5006 & & 90.95 & 1.062 \\
\hline$t / 4 * t / 4$ & 25,527 & 255 & 8961 & & 90.57 & 1.057 \\
\hline \multicolumn{7}{|l|}{ Authors' test D14-70-40 } \\
\hline$t / 2 * t / 2$ & 5833 & 0 & 633 & 13.65 & 13.99 & 1.025 \\
\hline$t / 3 * t / 3$ & 9709 & 66 & 3025 & & 13.75 & 1.007 \\
\hline$t / 4 * t / 4$ & 15,325 & 163 & 6221 & & 13.53 & 0.991 \\
\hline
\end{tabular}


Table 3

Comparison of test and simulation results for connection failure load.

\begin{tabular}{|c|c|c|c|c|c|c|}
\hline Test ID & $\begin{array}{l}\text { End distance } \\
(\mathrm{mm})\end{array}$ & $\begin{array}{l}\text { Edge distance } \\
(\mathrm{mm})\end{array}$ & $\begin{array}{l}\text { Recorded failure } \\
\text { load }(\mathrm{kn})\end{array}$ & $\begin{array}{l}\text { Simulated failure } \\
\text { load (kn) }\end{array}$ & $\begin{array}{l}\text { Recoded failure } \\
\text { mode }\end{array}$ & Simulated failure mode \\
\hline D14-14-28 & 14 & 14 & 7.41 & 6.49 & End pull-out & End pull-out \\
\hline D14-20-80 & 20 & 40 & 12.00 & 10.92 & End pull-out & End pull-out (see Fig. 4) \\
\hline D14-28-80 & 28 & 40 & 15.96 & 14.43 & End pull-out & End pull-out \\
\hline D14-21-42 & 21 & 21 & 11.58 & 10.88 & End pull-out & End pull-out \\
\hline D14-70-40 & 70 & 20 & 13.65 & 13.46 & Net-section & Net-section (see Fig. 4) \\
\hline D14-70-80 & 70 & 40 & 19.52 & 19.48 & Bearing & Bearing (see Fig. 4) \\
\hline
\end{tabular}
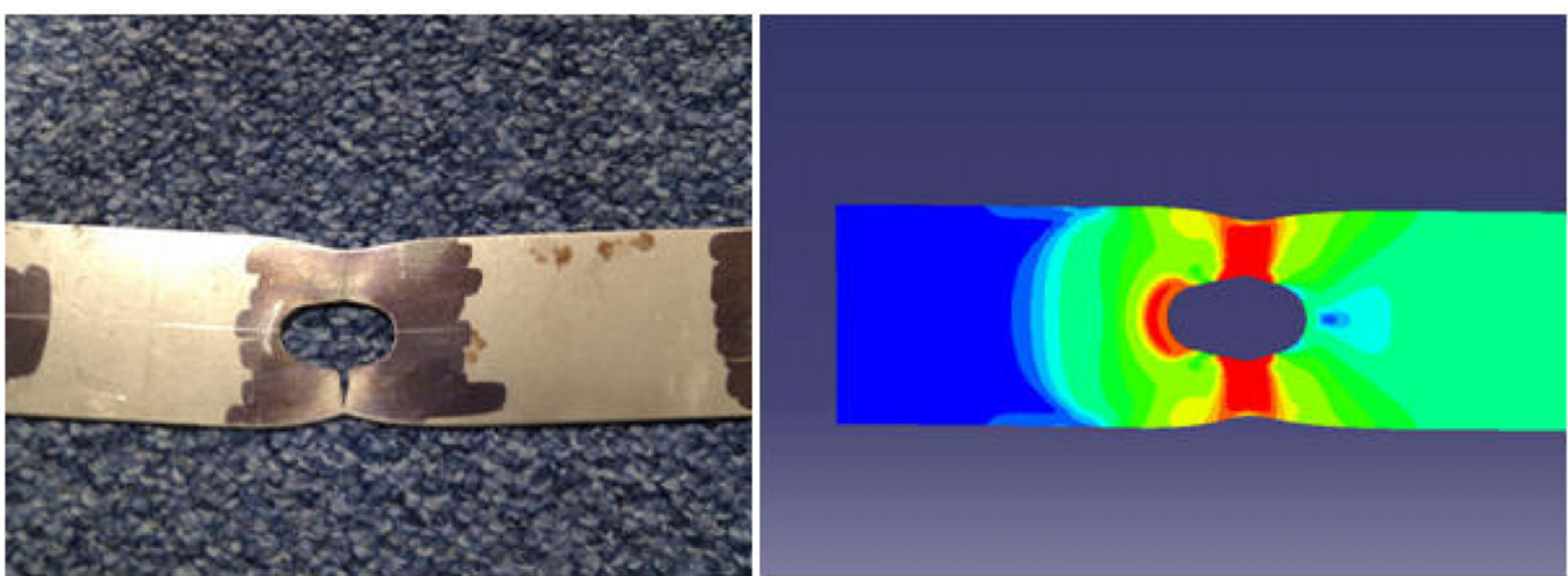

D14-70-40

Net section failure

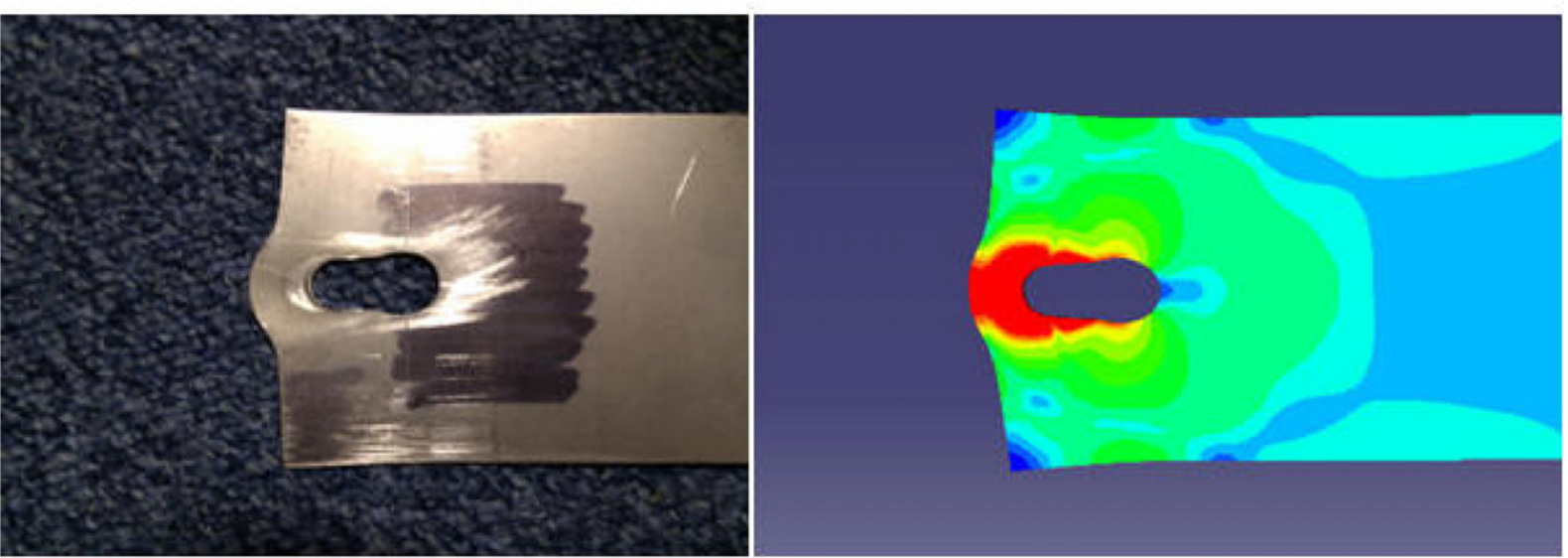

D14-20-80

End pull-out failure
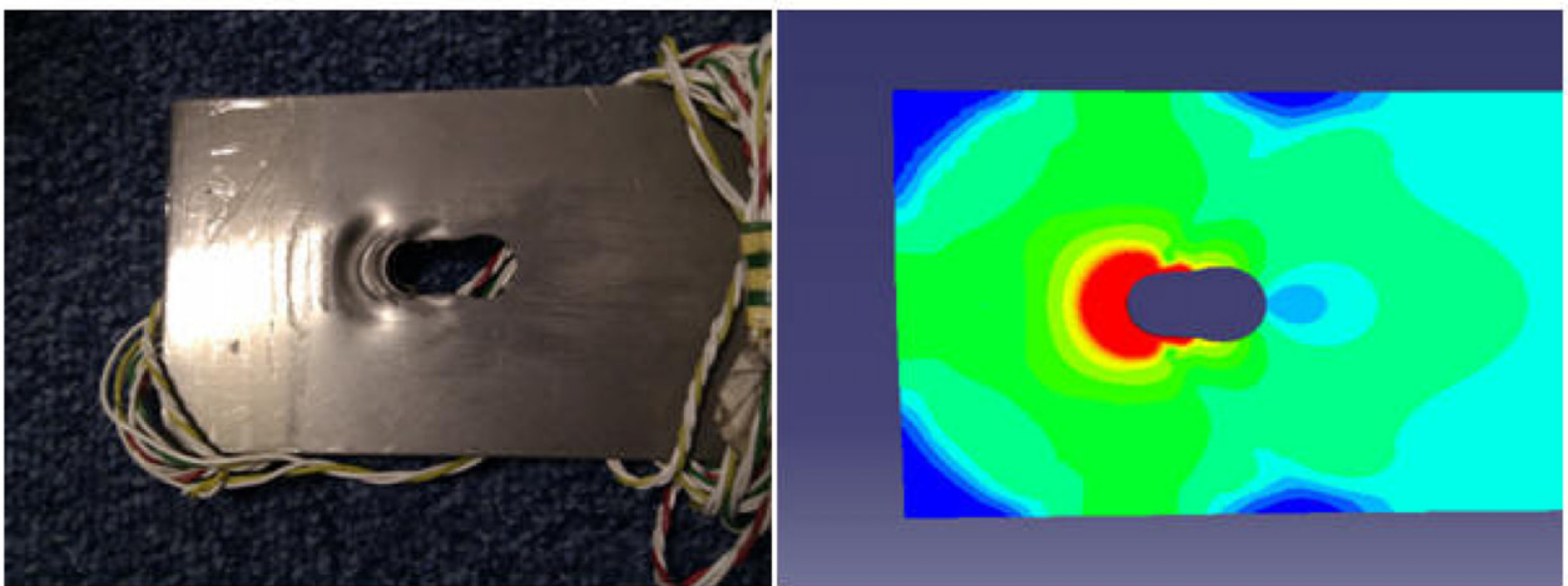

D14-70-80

\section{Bearing failure}

Fig. 4. Comparison of test and FE simulated failure modes. 


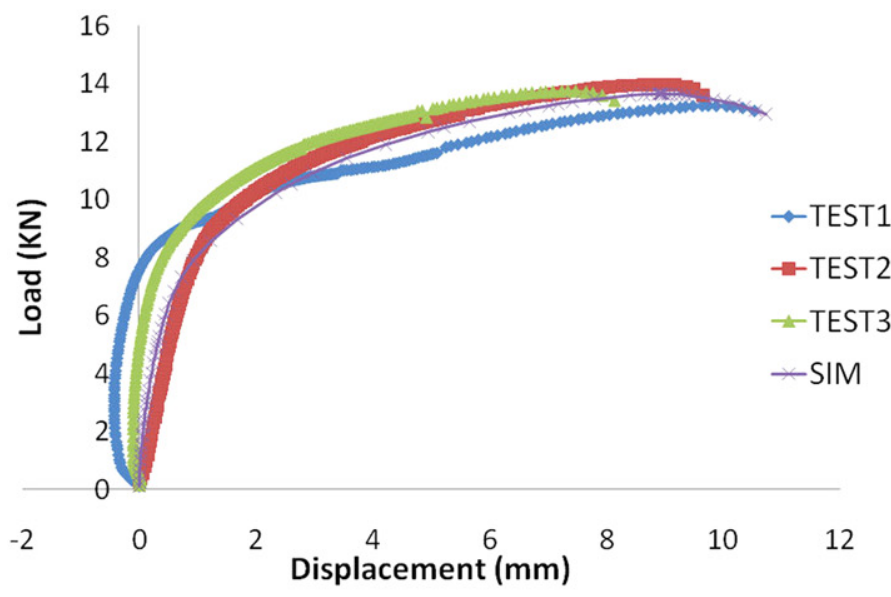

D14-70-40

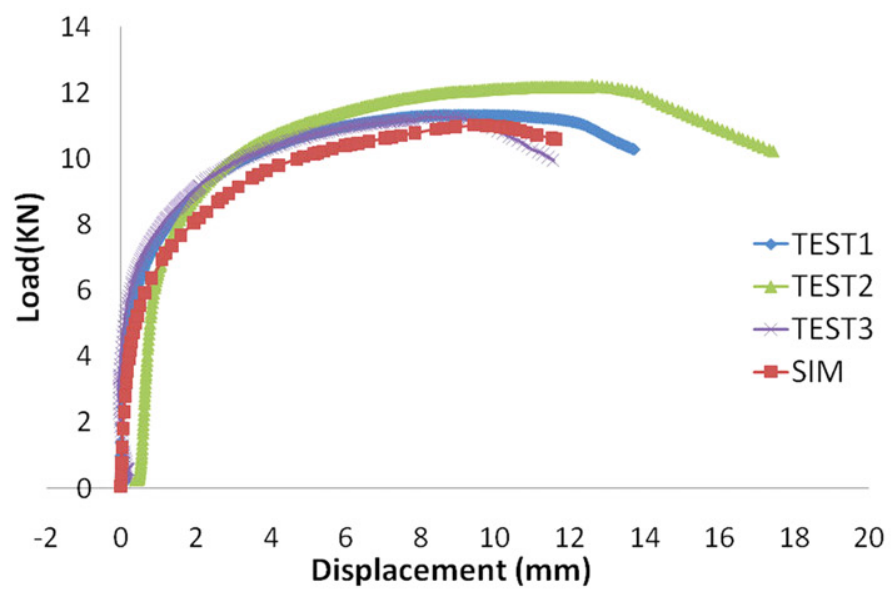

D14-21-42

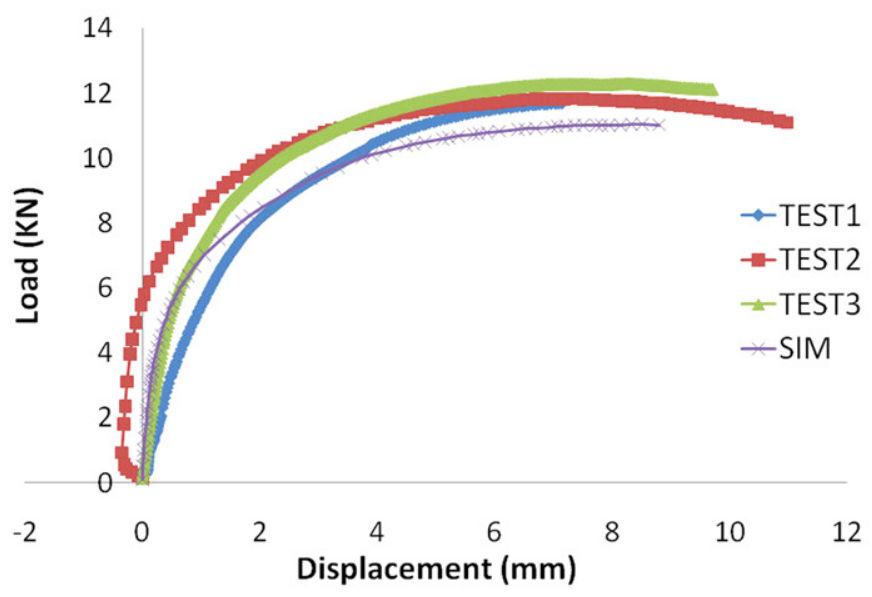

D14-20-80

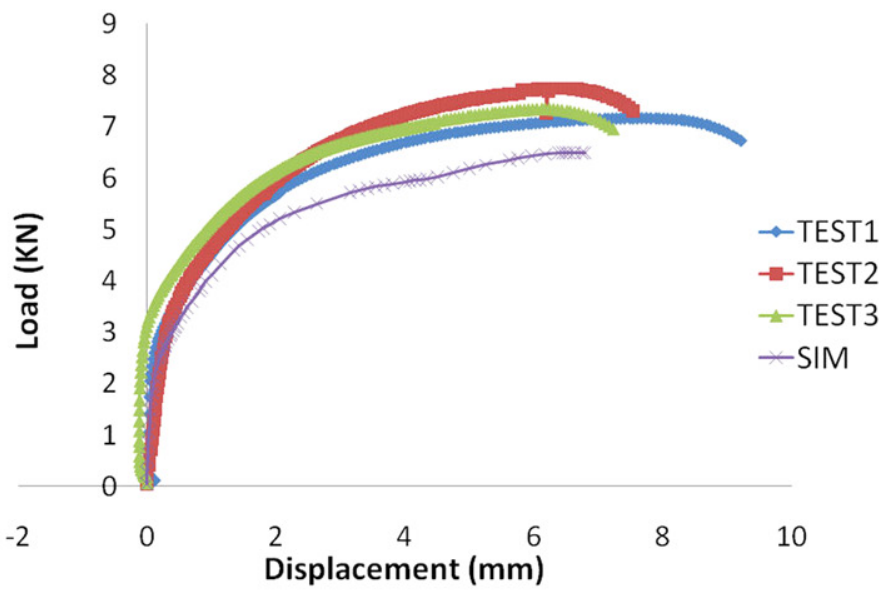

D14-14-28

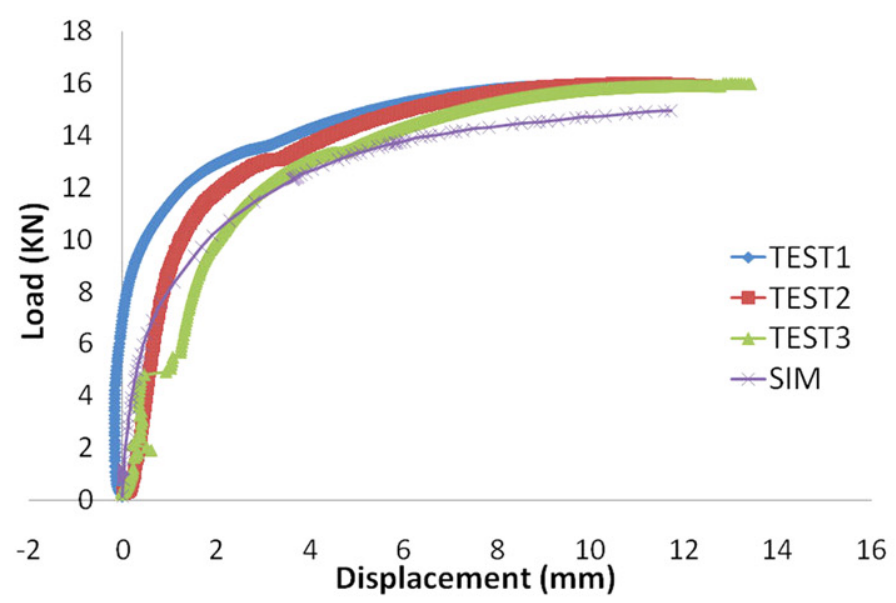

D14-28-80

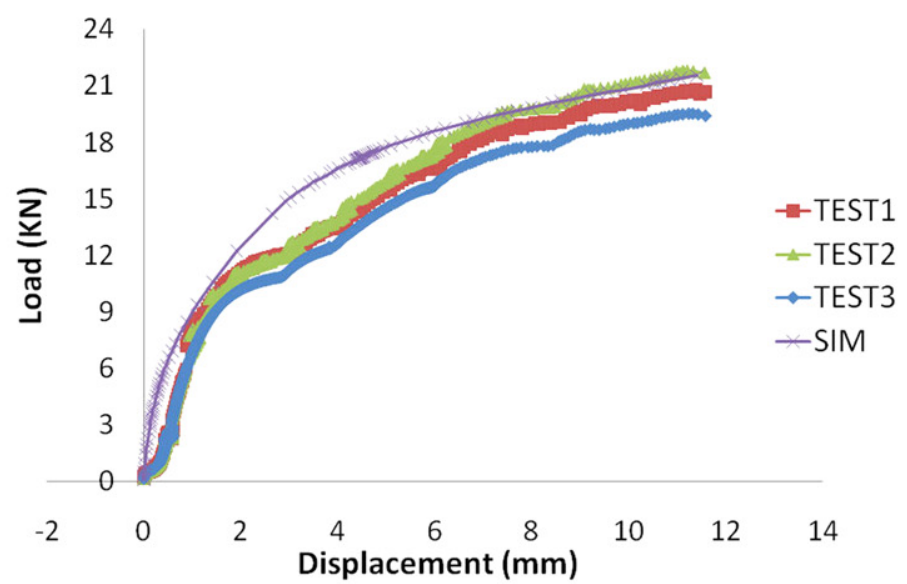

D14-70-80

Fig. 5. Comparison of test and simulation load-displacement results for all tests.

The results in Fig. 6 show that the finite element model accurately simulated all the load-strain relationships except for one case (end pull-out strain at point 1 and 2) which was caused by strain gauge failure due to large deformation of the plate at the strain gauge area, as shown in Fig. 7.

From the above comparisons, it can be accepted that the FE model is sufficiently accurate and can be used to investigate the behaviour of this type of structure for the development of an analytical method.

\section{Parametric study and development of analytical load- deflection curve}

\subsection{Parametric study}

In order to develop an analytical model to predict the loaddeflection behaviour of thin-walled steel plates loaded by a single bolt in shear, an extensive set of parametric studies were performed 

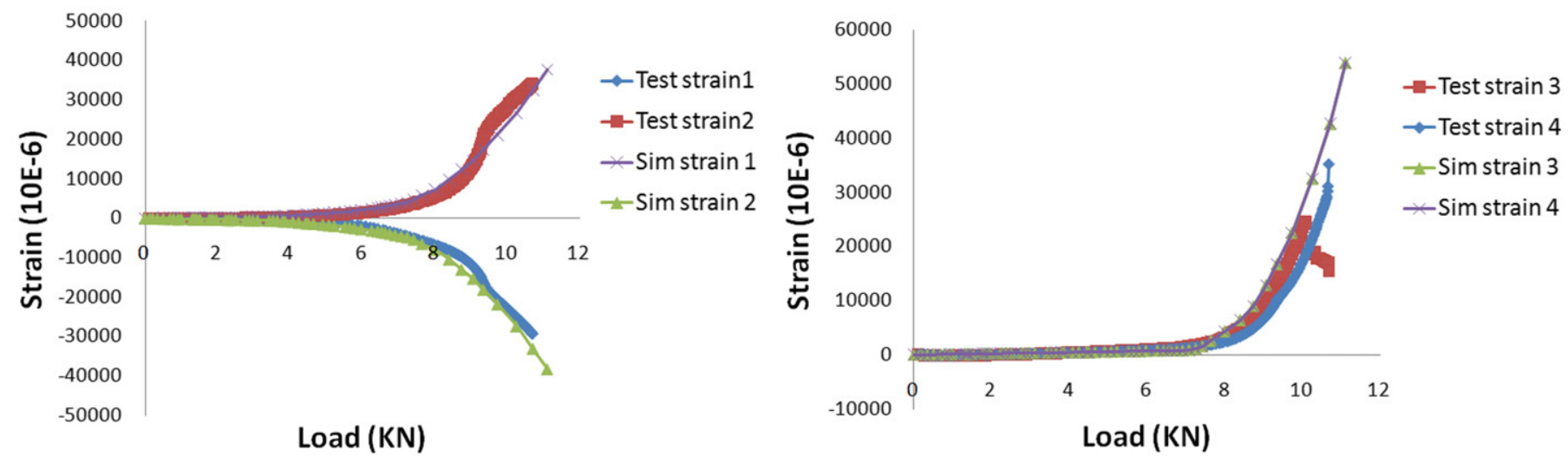

\section{D14-70-40 load-strain curves comparison}
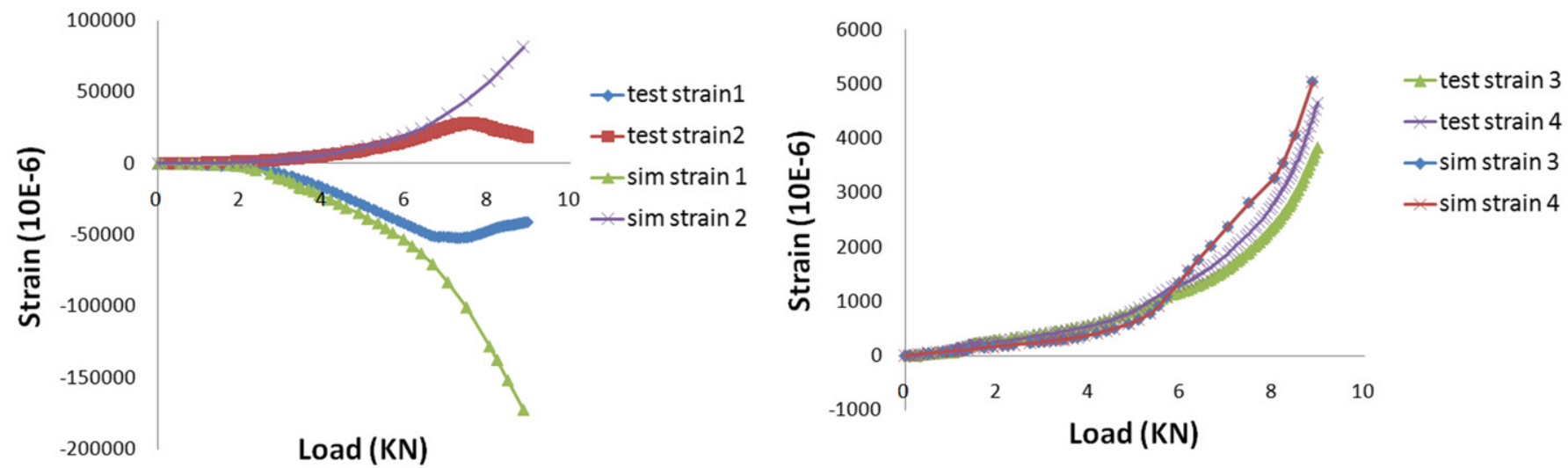

\section{D14-20-80 load-strain curves comparison}

Fig. 6. Comparison of recorded and simulated load-strain curves.

to establish a comprehensive database of results. Table 4 lists the parameters investigated, intended to assess the effects of the following parameters: bolt-hole size, end distance, edge distance and ultimate strain of steel. In total 56 simulations are performed.

\subsection{Determination of key values in analytical load-deflection curve}

The analytical load-deflection curve is assumed to be linearelastic-plastic, as shown in Fig. 8. Therefore, three values are required to determine the analytical curve: initial stiffness, strength and deformation capacity.

\subsubsection{Initial stiffness}

Eurocode 3 provides the following equation for calculating bolt bearing initial stiffness:

$k=24 n_{b} k_{b} k_{t} d f_{u}$ where $k_{b}$ is a factor that considers the effect of end distance and bolt row spacing and $k_{b}=\min \left\{k_{b 1}, k_{b 2}, 1.25\right\}$ with $k_{b 1}=0.25 e_{1} /$ $d+0.5, k_{b 2}=0.25 p_{1} / d+0.375, k_{t}=1.5 t_{j} / d_{M 16}$ which is a reduction factor for steel plate thickness and $d_{M 16}$ : nominal diameter of a M16 bolt.

This formula is intended for use with hot-rolled steel connection. However, close agreement between the test, simulation and analytical calculation results in Table 5 suggests that it can also be used to predict initial bearing stiffness for cold-formed thinwalled steel connections.

\subsubsection{Strength}

There are three possible failure modes: net section tensile fracture, end pull-out and bearing failure.

The net section tensile fracture capacity is

$F_{t}=A_{n} f_{u}=\left(2 e_{2}-d\right) t f_{u}$ 
In an earlier version of Eurocode 3 [9], the end pull-out capacity was calculated using

$F_{s}=t e_{1} f_{u} / 1.2$

And the bearing resistance was calculated using

$F_{b, R d}=2.5 d t f_{u}$

but $F_{b, R d} \leq t e_{1} f_{u} / 1.2$

In the latest version of Eurocode 3 [10], the above two equations are combined to give the following single equation:

$F_{b, R d}=2.5 \alpha_{b} k_{t} f_{u} d t$

where $k_{t}$ is 1 if there is no net section failure. $\alpha_{b}$ is taken as the smaller value of $e_{1} / 3 d$ (end pull-out) and 1 (bearing).

In the Australian/New Zealand [11] and North American design standards [12], the end pull-out resistance formula is similar, only the reduction factor 1.2 is excluded, i.e.

$F_{s}=t e_{1} f_{u}$

Table 6 compares the ABAQUS simulation results with predictions for connection strength from the different prediction methods. It appears that for end pull-out, the New Zealand/Australian standard of not including a modification factor of 1.2 gives better results.

From the comparisons for initial stiffness and load carrying capacity under different failure modes, it can be confirmed that the existing design calculation methods for these two quantities are sufficiently accurate.

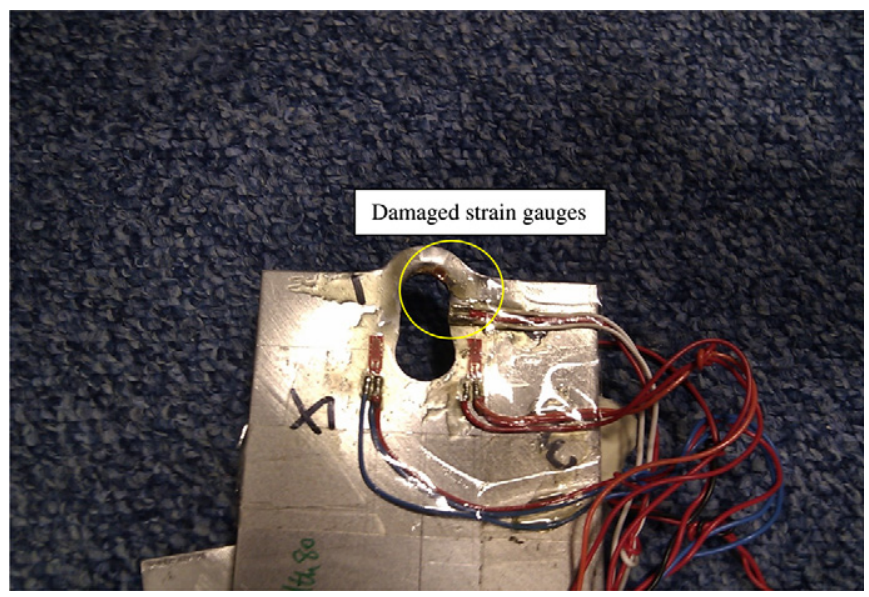

Fig. 7. Damaged strain gauges at point 1 and 2 of Test D14-20-80.

\subsubsection{Deformation capacity}

The main focus of the analytical load-deflection develop is to determine the connection deformation at the ultimate capacity.

Here the connection deformation refers to elongation of the bolt hole. Due to symmetry, bolt hole elongation is the tensile deformation of half of the bolt hole circumference plus any compressive pile up in front of the bolt, as indicated in Fig. 9. Therefore, to calculate the bolt-hole elongation, it is necessary to obtain the tensile strain distribution around the bolt hole and the compressive strain distribution in front of the bolt.

\subsection{Tensile strain distribution}

After detailed investigation of strain distributions around the bolt hole based on the parametric study results, it was found that

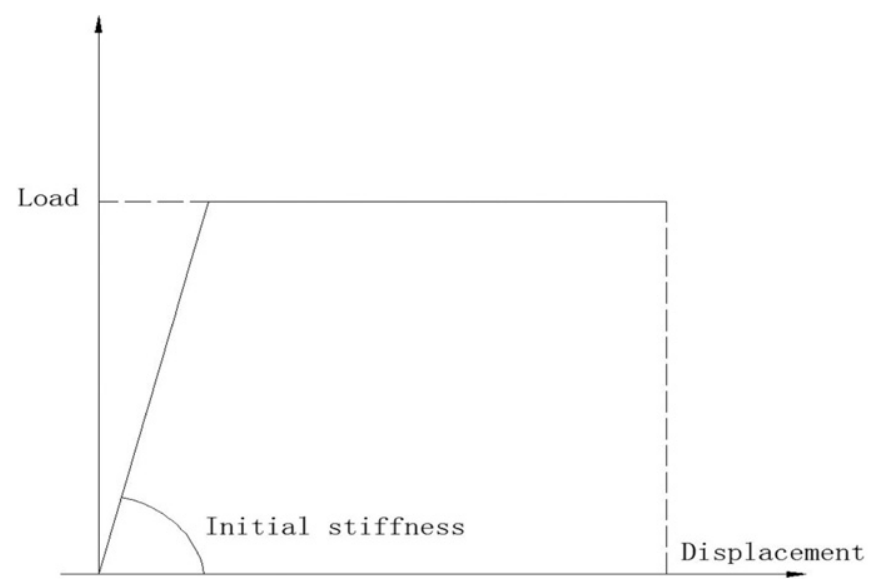

Fig. 8. Assumed analytical load-displacement curve.

Table 5

Comparison of initial stiffness from test, FE simulation and Eurocode 3 calculation.

\begin{tabular}{llrlll}
\hline Test ID & \multicolumn{1}{l}{$K_{1}$} & \multicolumn{1}{c}{$K_{2}$} & \multicolumn{1}{l}{$K_{3}$} & $K_{2} / K_{1}$ & $K_{3} / K_{1}$ \\
\hline D14-14-28 & 10,156 & 9366 & 11,290 & 0.92 & 1.11 \\
D14-20-80 & 12,222 & 14,709 & 12,945 & 1.20 & 1.06 \\
D14-28-80 & 11,297 & 15,774 & 15,053 & 1.40 & 1.33 \\
D14-21-42 & 12,580 & 15,785 & 13,171 & 1.25 & 1.05 \\
D14-70-40 & 13,820 & 16,167 & 18,816 & 1.17 & 1.36 \\
D14-70-80 & 14,032 & 16,258 & 18,816 & 1.16 & 1.34 \\
\hline
\end{tabular}

$K_{1}$ : initial stiffness from test.

$K_{2}$ : initial stiffness from ABAQUS simulation.

$K_{3}$ : initial stiffness from Eurocode 3 calculation.

Table 4

List of parameters in parametric study.

\begin{tabular}{|c|c|c|c|c|c|}
\hline Bolt size (mm) & Bolt hole size $d(\mathrm{~mm})$ & End distance $e_{1}$ & Edge distance $e_{2}$ & Thickness $t(\mathrm{~mm})$ & Ultimate strain of steel \\
\hline \multirow[t]{4}{*}{8} & \multirow[t]{4}{*}{10} & $1 d$ & $1 d, 1.5 d, 2 d, 2.5 d$ & 1.5 & 0.35 \\
\hline & & $2 d$ & $1 d, 1.5 d, 2 d, 2.5 d$ & 1.5 & 0.35 \\
\hline & & $3 d$ & $1 d, 1.5 d, 2 d, 2.5 d$ & 1.5 & 0.35 \\
\hline & & $4 d$ & $1 d, 1.5 d, 2 d, 2.5 d$ & 1.5 & 0.35 \\
\hline \multirow[t]{4}{*}{12} & \multirow[t]{4}{*}{14} & $1.5 d$ & $1 d, 1.5 d, 2 d, 2.5 d$ & $1.5,3$ & 0.35 \\
\hline & & $2 d$ & $1 d, 1.5 d, 2 d, 2.5 d$ & 1.5 & $0.25,0.35$ \\
\hline & & $3 d$ & $1 d, 1.5 d, 2 d, 2.5 d$ & 1.5 & 0.35 \\
\hline & & $4 d$ & $1 d, 1.5 d, 2 d, 2.5 d$ & 1.5 & 0.35 \\
\hline \multirow[t]{4}{*}{18} & \multirow[t]{4}{*}{20} & $1 d$ & $1 d, 1.5 d, 2 d, 2.5 d$ & 1.5 & 0.35 \\
\hline & & $2 d$ & $1 d, 1.5 d, 2 d, 2.5 d$ & 1.5 & 0.35 \\
\hline & & $3 d$ & $1 d, 1.5 d, 2 d, 2.5 d$ & 1.5 & 0.35 \\
\hline & & $4 d$ & $1 d, 1.5 d, 2 d, 2.5 d$ & 1.5 & 0.35 \\
\hline
\end{tabular}




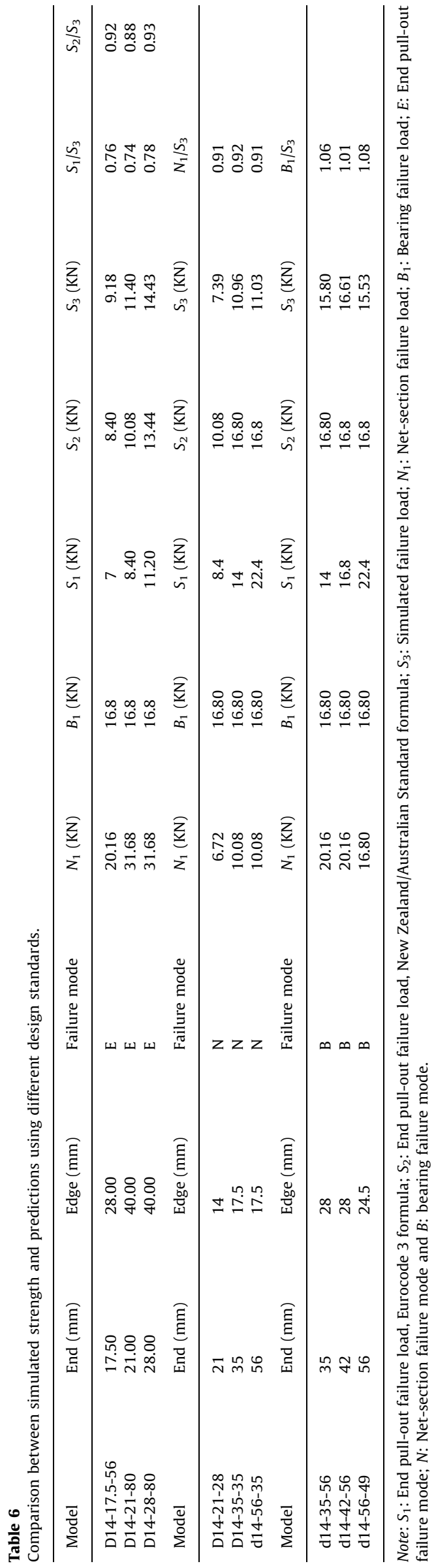

the tensile strain distribution around the bolt hole may be assumed to be multi-linear between five key points, as shown in Fig. 9. The strain at points $\mathrm{D}$ and $\mathrm{E}$ may be assumed to be 0 .

The tensile strain values at points $A, B$ and $C$ are dependent on the connection failure mode. As explained in the previous section, there are three pure failure modes: net section tension failure, end pull-out and bearing failure. For strain calculations, the following three mixed failure modes should also be considered to avoid a step change in strain values at the critical points: net section tension/end pull-out, net section tension/bearing, end pull-out/bearing. Fig. 10 compares the assumed tensile strain distributions around the hole (to be presented in the next section) with the numerical simulation results for different failure modes. The assumed strain distributions can be considered acceptable.

\subsubsection{Net section failure}

For net section failure, it is assumed that the strain at point $\mathrm{C}$ is equal to the ultimate tensile strain of steel. For example, Fig. 11 shows that the ultimate tensile strain of steel was 0.35 (cf Table 4). The strain at points A, B, D and E is zero. Fig. 11 shows the assumed strain distribution around the bolt hole.

Net section failure occurs when: $F_{t}<F_{s}$ and $F_{t}<F_{b}$. Therefore

$F_{t}=A_{n} f_{u}=\left(2 e_{2}-d\right) t f_{u}<F_{s}=t e_{1} f_{u}$

$F_{t}<F_{b}=2.5 f_{u} d t$

Re-arranging the above equations gives

$e_{2}<\left(e_{1}+d\right) / 2$

$e_{2}<1.75 d$

\subsubsection{Pull-out failure}

Pull-out failure happens when $F_{s}<F_{t}$ and $F_{s}<F_{b}$. Therefore

$F_{s}=t e_{1} f_{u} \leq F_{t}=A_{n} f_{u}=\left(2 e_{2}-d\right) t f_{u}$

$F_{s} \leq F_{b}=2.5 f_{u} d t$

Re-arranging the above equations gives

$e_{1} \leq 2 e_{2}-d$

$e_{1} \leq 2.5 d$

When end pull-out happens, it is assumed that the strain at point $\mathrm{C}, \mathrm{D}$ and $\mathrm{E}$ is zero but the strain at $\mathrm{B}$ reaches $\varepsilon_{B}=\varepsilon_{t}+\mu \varepsilon_{r}$, where $\varepsilon_{t}$ is the ultimate tensile strain of steel, $\mu$ Poisson's ratio (0.3) and $\varepsilon_{r}$ is the radial compressive strain due to bearing. It is assumed that $\varepsilon_{r}=1.0$. Therefore, in Fig. 12, the tensile strain at point $B$ is $0.35+0.3 * 1.0=0.65$.

The tensile strain at point $A$ equals to the ultimate tensile strain of the steel material, e.g. 0.35 in Fig. 12.

\subsubsection{Bearing failure}

Bearing failure happens when $F_{b} \leq F_{t}$ and $F_{b} \leq F_{s}$. These conditions are met when

$e_{2} \geq 1.75 d$

$e_{1} \geq 2.5 d$

When bearing failure happens, it is assumed that the strains at point $\mathrm{C}, \mathrm{D}$ and $\mathrm{E}$ are zero. The strain at point $\mathrm{A}$ is $\varepsilon_{B}=\varepsilon_{t}+\mu \varepsilon_{r}$ owing to combined tension and compression in front of the bolt. For example, in Fig. 13, the strain at point $A$ is $0.35+0.3 *$ $1.0=0.65$. The strain distribution between $A$ and $C$ is linear so the strain at point $B$ is half of that at point A. Fig. 13 shows the complete assumed tensile strain distribution around the bolt hole under bearing failure. 


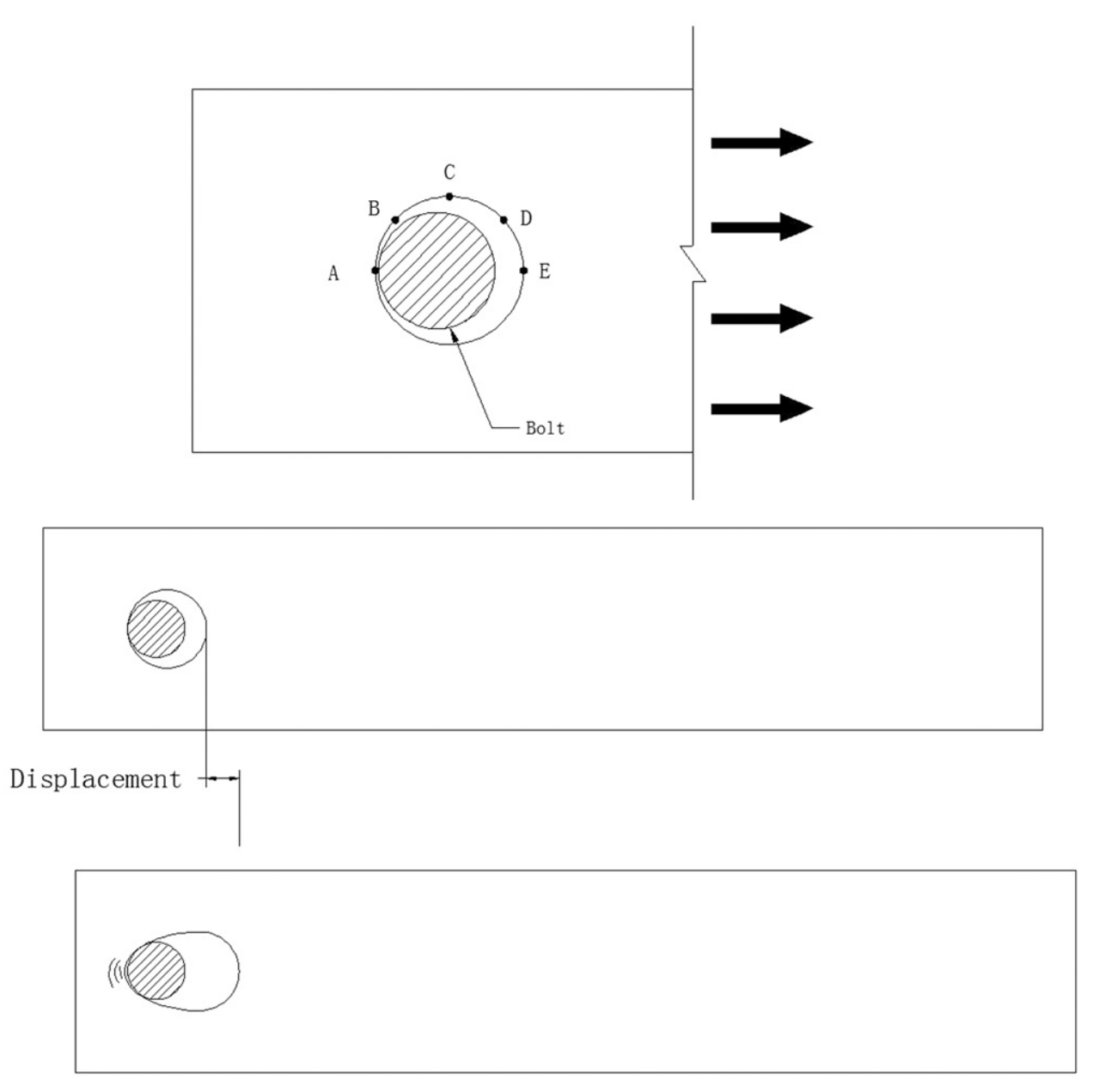

Fig. 9. Positions of critical strain points.

\section{Mixed failure modes}

In the previous section, strain distributions are given for one single failure mode. One single failure mode occurs when the load carrying capacity under this failure mode is much lower than those of the other two failure modes. However, when the calculated failure loads under two different failure modes are similar, using the above strain distributions would introduce artificial step changes. Modifications are therefore necessary to allow a smooth and gradual transition from one failure mode to another.

It is hard to decide exactly when mixed failure mode or pure single failure mode occurs. In order to determine the critical point strain values, approximate boundaries are assumed based on the simulation results.

\subsection{Type I: mixed net-section/end pull-out failure}

According to Eqs. (9) and (11), net section/end pull-out failure is determined by the ratio of $e_{1} /\left(2 e_{2}-d\right)$. When this value is less than 1 , end pull-out dominates and when this is greater than 1 , net section failure dominates. Also since bearing failure does not happen, therefore, $e_{1}<2.5 d$ and $e_{2}<1.75 d$. It is assumed that at $e_{1} /\left(2 e_{2}-d\right)=1$, the strain values at critical points A, B and C are according to end pull-out failure. The transition period is from when $e_{2}=\left(e_{1}+d\right) / 2$ to a reduction in $e_{2}$ by $0.25 d$ when the strain values at critical points $A, B$ and $C$ are calculated for net-section failure. Within the transition region, linear interpolation is used. Fig. 14 shows the assumed strain distributions at points A, B and C as function of $e_{2}$.

\subsection{Type II mixed net-section/bearing failure}

For mixed net-section/bearing failure, end pull-out failure does not occur. Therefore, $e_{1}>2 e_{2}-d$ and $e_{1}>2.5 d$. According to Eqs. (10) and (13), the condition $e_{2}=1.75 d$ marks the separation of net-section failure from bearing failure. It is assumed that at $e_{2}=1.75 d$, the strain distribution is according to bearing failure. Pure net-section failure happens when $e_{2}<0.75 d$. During the transition period of $0.75 d<e_{2}<1.75 d$, linear interpolation can be used. Fig. 15 shows the assumed strain values at increasing $e_{2}$.

\subsection{Type III mixed end pull-out/bearing failure}

For this mixed mode, net-section failure does not occur. Therefore, according to Eqs. (11) and (13), $e_{1}<2 e_{2}-\mathrm{d}$ and $e_{2}>1.75 d$. The boundary between end pull-out failure and bearing failure is at $e_{1}=2.5 \mathrm{~d}$. It is assumed that at $e_{1}=2.5 \mathrm{~d}$, bearing failure starts to control. The transition zone is between $e_{1}=1.5 \mathrm{~d}$ and $e_{1}=2.5 d$. At $e_{1}=1.5 d$, end pull-out governs and the strain values are according to end pull-out failure. Fig. 16 shows the strain values at the different critical points at increasing $e_{1}$.

\subsection{Compressive strain distribution}

Compression strain is used to calculate plate pile up, therefore, compressive strain is only considered at point $C$ (directly in front of the bolt). Although compression in front of the bolt will exist in all cases, significant compressive strain occurs under bearing 


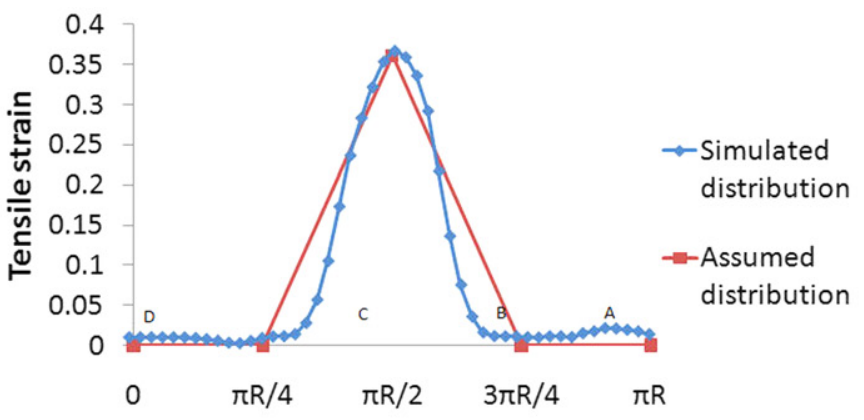

Circumferential distance (start from opposite of compression centre)

Pure net-section failure

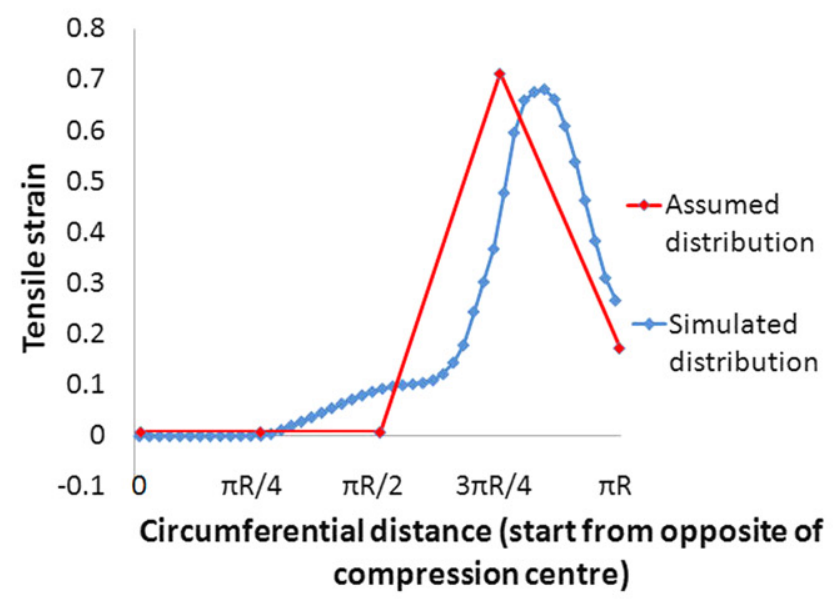

Pure end pull-out failure

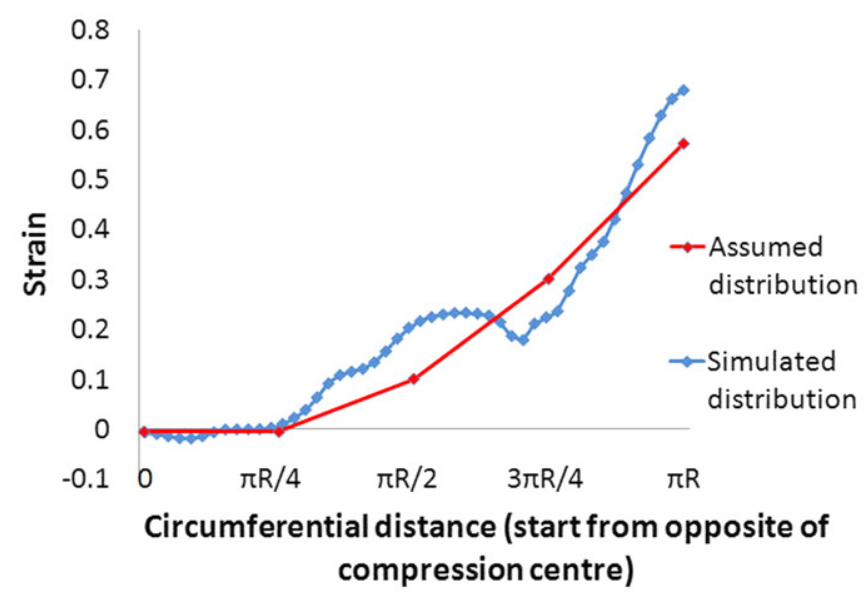

Type II net-section to bearing mixed failure

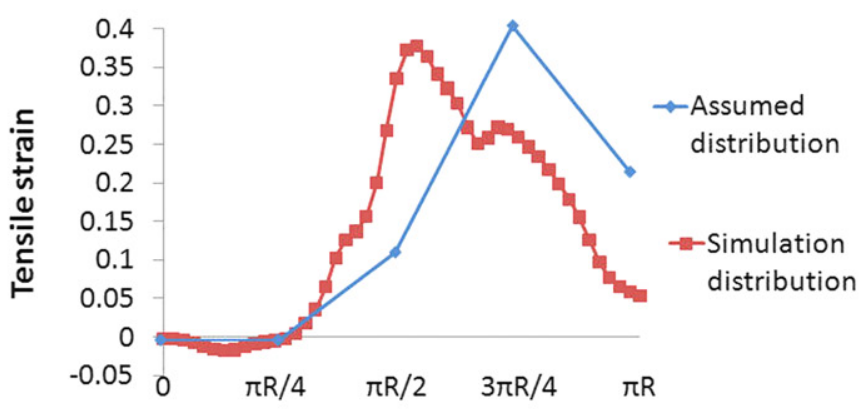

Circumferential distance (start from opposite of compression centre)

Type I net-section to end pull-out mixed failure

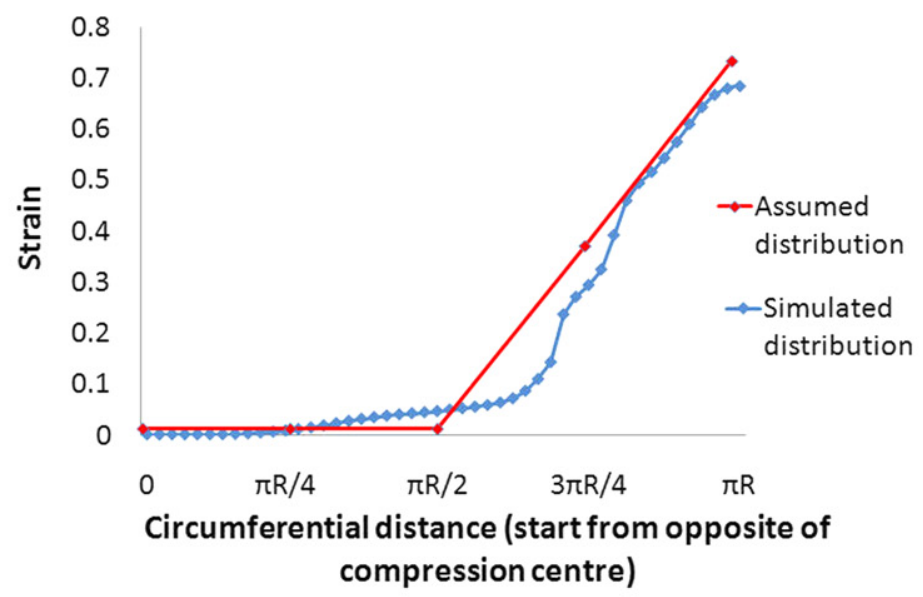

Pure bearing failure

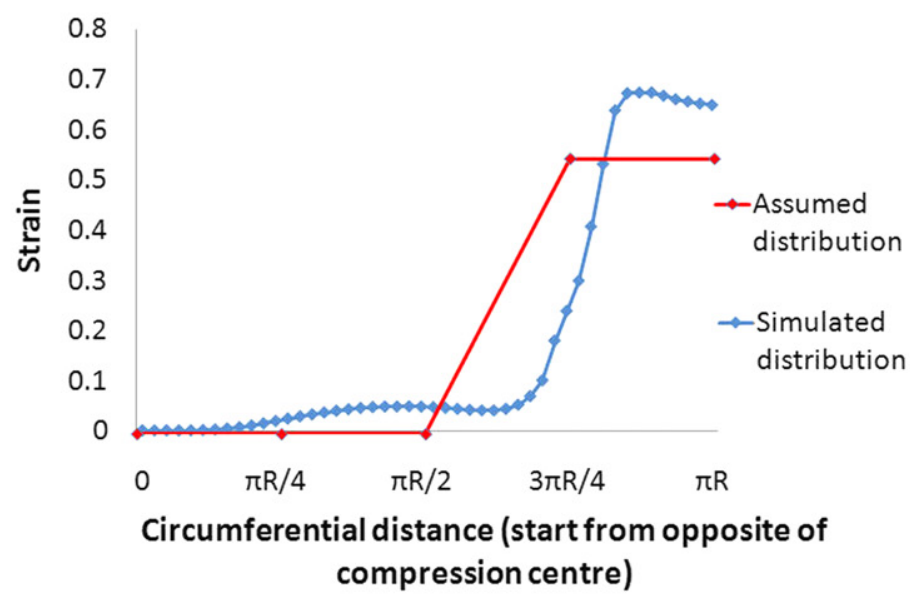

Type III end pull-out to bearing mixed failure

Fig. 10. Comparison between assumed strain distribution and simulated strain distribution for different failure modes.

or end pull-out failure. This happens when $e_{2}>\left(e_{1}+d\right) / 2$ and $e_{2}>1.75 d$. It is assumed that when the end distance is at $e_{1}=1.2 d$ (minimum requirement of Eurocode 3 ), end pull-out failure controls and the maximum compressive strain value is equal to the steel ultimate tensile strain. At $e_{1}=2 d$, bearing failure governs and the compressive strain reaches 1.0. Linear interpolation applies during the transition phase.

Nevertheless, for plates that experience net-section failure mode, there is some compression strain, although the compressive strain is reduced compared to the other two failure modes. According to Eqs. (9) and (10), net-section failure occurs when $e_{2}<\left(e_{1}+d\right) / 2$ and $e_{2}<1.75 d$. Within this failure mode, the numerical simulation results suggest that when $e_{2} \leq 0.75 d$, the compressive strain equals 0 . When $e_{2} \geq\left(e_{1}+d\right) / 2$, the edge distance is sufficient to achieve the maximum compressive strain specified in the last paragraph. When the edge distance falls between these two values, linear interpolation can be applied to determine the reduced compressive strain value. 


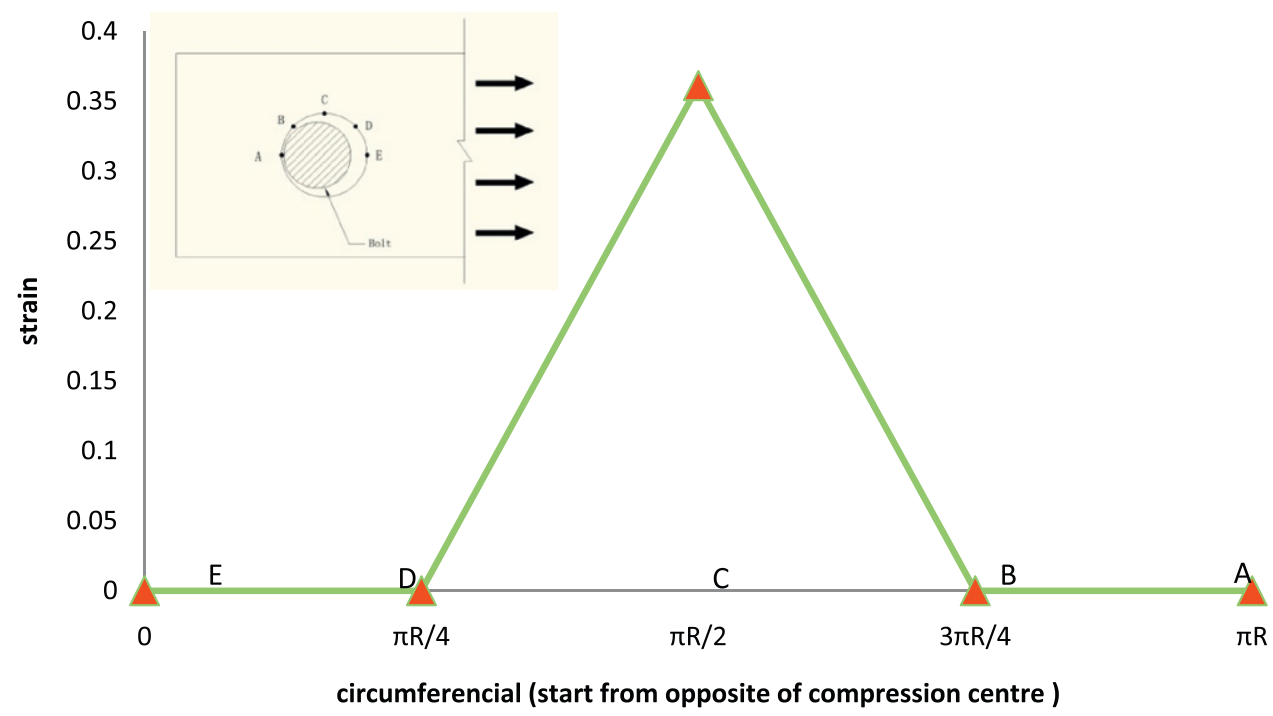

Fig. 11. Assumed tensile strain distribution for net-section failure.

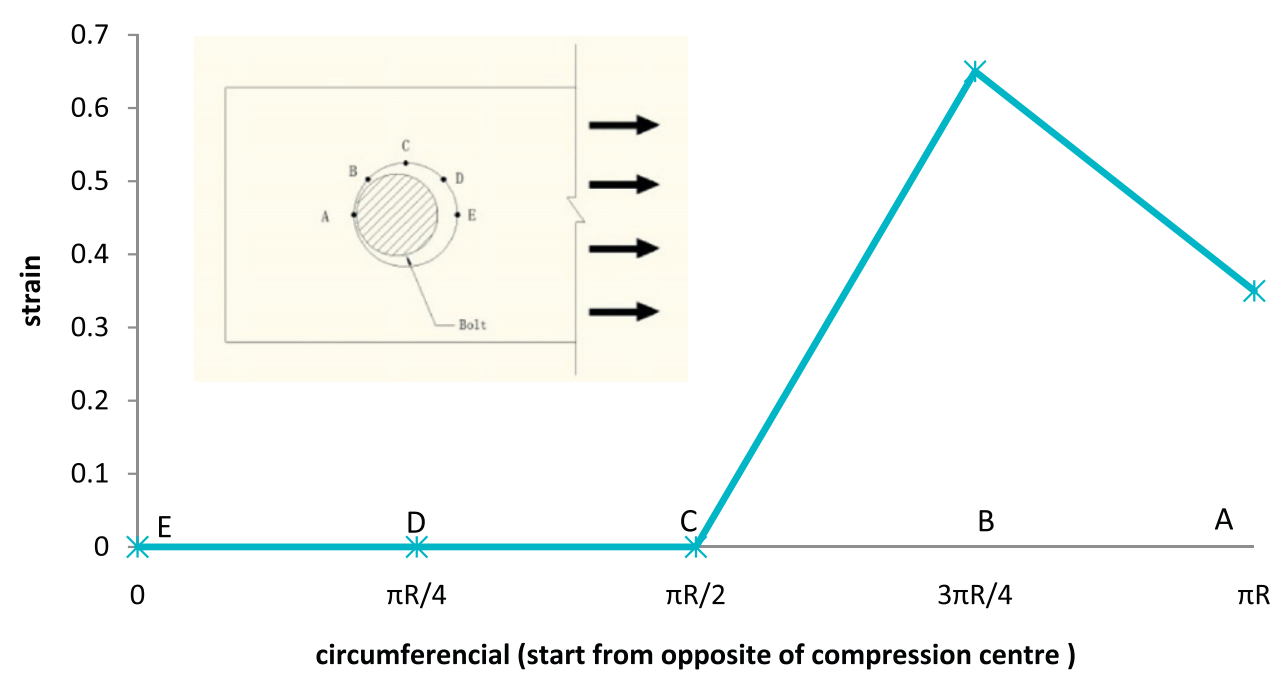

Fig. 12. Assumed tensile strain distribution for end pull-out failure.

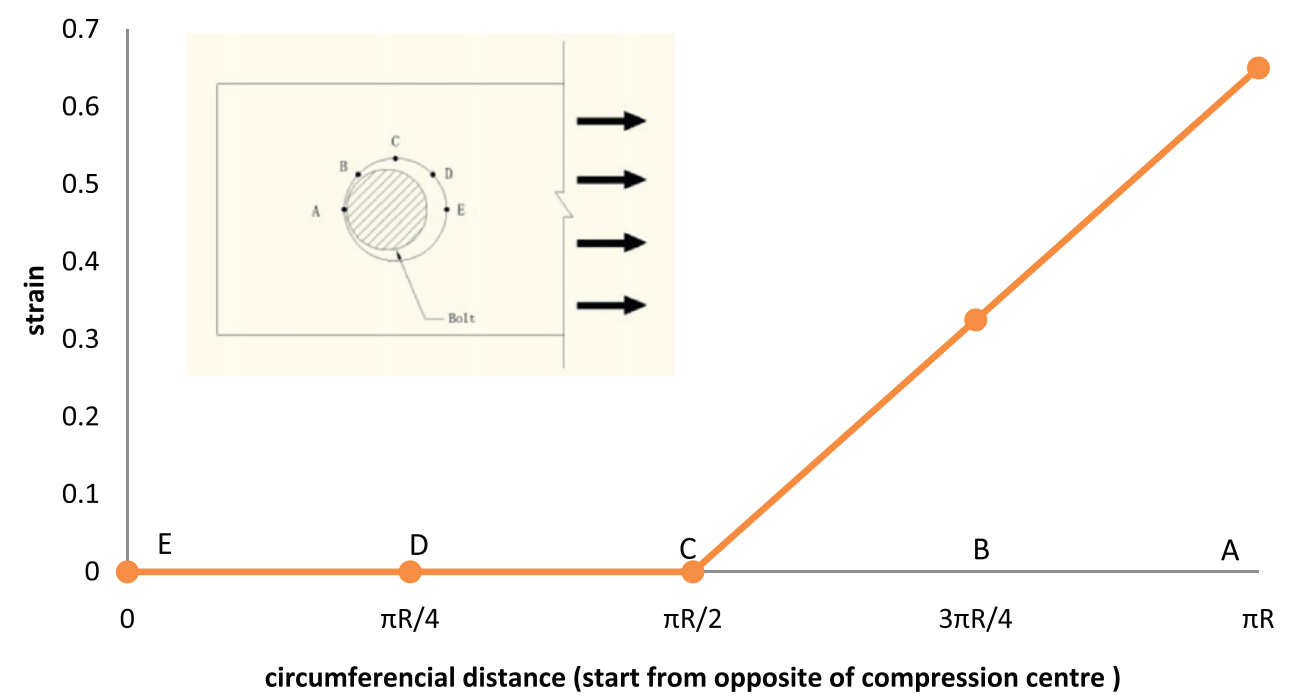

Fig. 13. Assumed tensile strain distribution for bearing failure. 


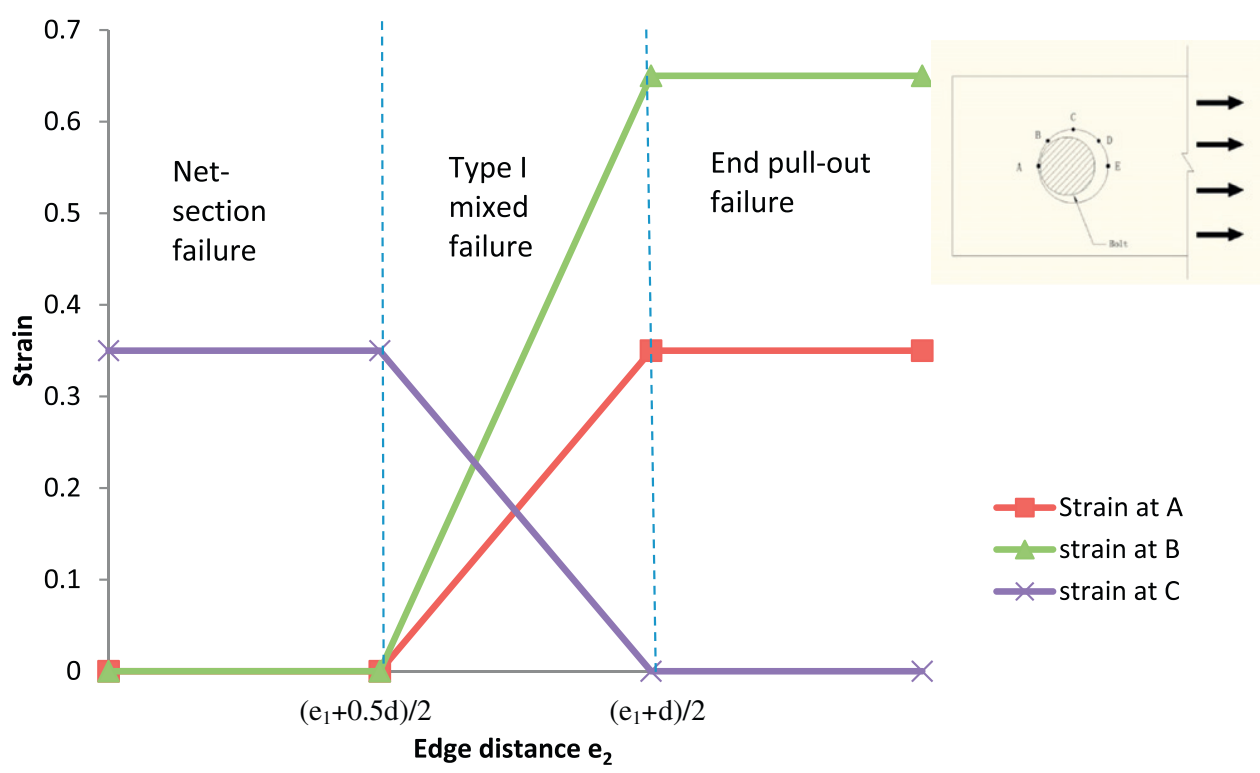

Fig. 14. Strains at different critical points during transition from net section failure to end pull-out failure.

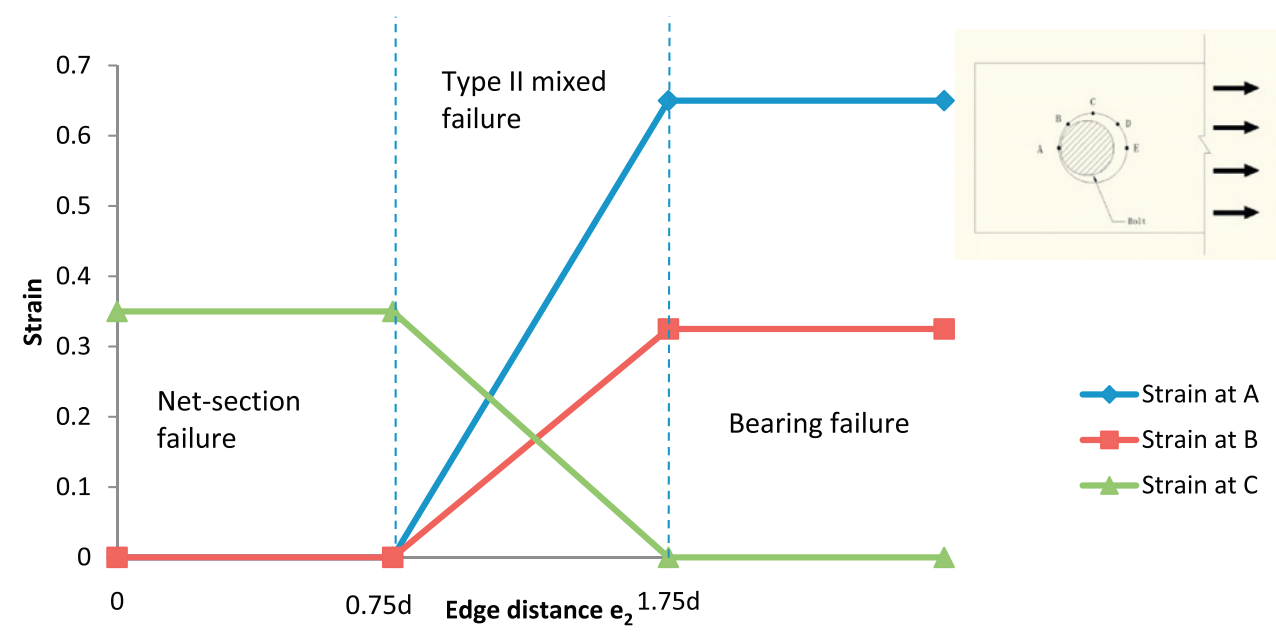

Fig. 15. Strain values at different critical points during transition from net-section to bearing failure.

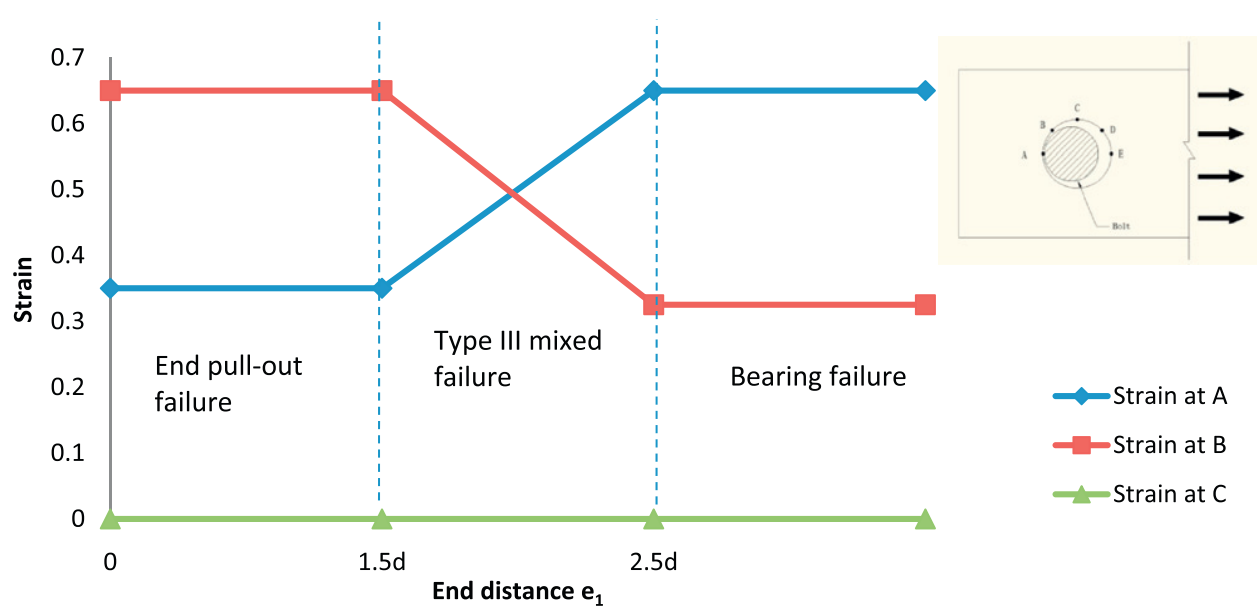

Fig. 16. Assumed strain values at different critical points for transition from end pull-out to bearing failure.

In order to calculate the bolt hole elongation due to compressive pile up, it is assumed that that the compressive strain changes from the maximum value at the bolt/ plate contact point to zero at a distance of one bolt diameter away (or the actual edge of the plate if less), as shown in Fig. 17.

It should be pointed out that some of the low values of edge and end distances may be outside the range of the permitted edge 
and end distances by design standards. However, these limits were not enforced so that the proposed analytical mode is generally applicable, including when the end and edge distances fall within the permitted ranges.

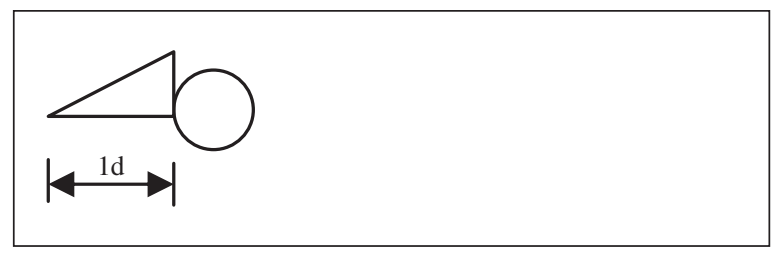

Fig. 17. Compressive strain distribution along plate length.
An example is provided in the Appendix to show how to calculate the strains at the various critical locations and the resulting bolt hole elongation.

To validate the above proposed analytical method, a series of parametric studies have been carried out using ABAQUS, covering different end and edge distances. In most simulations, the bolt diameter was $12 \mathrm{~mm}$, the plate thickness $1.5 \mathrm{~mm}$ and the steel ultimate tensile strain 0.35 . But simulations using other values of bolt diameter ( 8 and $18 \mathrm{~mm}$ ), plate thickness $(3 \mathrm{~mm}$ ) and steel ultimate tensile strain $(0.25)$ were also performed to check applicability of the proposed analytical method to different bolt sizes, plate thickness and steel ultimate tensile strain.

Table 7 compares the ABAQUS simulation results and the analytical results. Fig. 18 summarizes the comparison. The agreement

Table 7

Comparison between simulation and proposed calculation displacements.

\begin{tabular}{|c|c|c|c|c|c|c|c|c|c|c|}
\hline $\begin{array}{l}\text { End-edge } \\
\text { distance }\end{array}$ & $\begin{array}{l}\text { Model } \\
\text { name }\end{array}$ & $\begin{array}{l}\text { End distance } \\
e_{1}(\mathrm{~mm})\end{array}$ & $\begin{array}{l}\text { Edge distance } \\
e_{2}(\mathrm{~mm})\end{array}$ & $\begin{array}{l}\text { Bolt } \\
\text { hole } \\
d(\mathrm{~mm})\end{array}$ & $\begin{array}{l}\text { Ultimate } \\
\text { strain }\end{array}$ & $\begin{array}{l}\text { Thickness } \\
t(\mathrm{~mm})\end{array}$ & $\begin{array}{l}\text { Failure } \\
\text { modes }\end{array}$ & $\begin{array}{l}\text { FE model displacement } \\
\left(D_{1}\right)(\mathrm{mm})\end{array}$ & $\begin{array}{l}\text { Calculated result } \\
\left(D_{2}\right)(\mathrm{mm})\end{array}$ & $D_{2} / D_{1}$ \\
\hline $1.5 d-1 d$ & $21-28$ & 21 & 14 & 14 & 0.35 & 1.5 & $\mathrm{~N} / \mathrm{E}$ & 4.42 & 4.02 & 0.91 \\
\hline $1.5 d-1.5 d$ & $21-42$ & 21 & 21 & 14 & 0.35 & 1.5 & $\mathrm{E}$ & 7.93 & 8.67 & 1.09 \\
\hline $1.5 d-2 d$ & $21-56$ & 21 & 28 & 14 & 0.35 & 1.5 & $\mathrm{E}$ & 7.29 & 8.67 & 1.18 \\
\hline $1.5 d-2.5 d$ & $21-80$ & 21 & 40 & 14 & 0.35 & 1.5 & $\mathrm{E}$ & 6.97 & 8.67 & 1.24 \\
\hline $1.5 d-1 d$ & $21-28$ & 21 & 14 & 14 & 0.35 & 3 & $\mathrm{~N} / \mathrm{E}$ & 4.42 & 4.02 & 0.91 \\
\hline $1.5 d-1.5 d$ & $21-42$ & 21 & 21 & 14 & 0.35 & 3 & $\mathrm{E}$ & 8.51 & 8.67 & 1.02 \\
\hline $1.5 d-2 d$ & $21-56$ & 21 & 28 & 14 & 0.35 & 3 & $\mathrm{E}$ & 8.65 & 8.67 & 1.00 \\
\hline $1.5 d-2.5 d$ & $21-80$ & 21 & 40 & 14 & 0.35 & 3 & $\mathrm{E}$ & 7.24 & 8.67 & 1.20 \\
\hline $2 d-1 d$ & $28-28$ & 28 & 14 & 14 & 0.35 & 1.5 & $\mathrm{~N} / \mathrm{E}$ & 3.58 & 4.56 & 1.27 \\
\hline $2 d-1.5 d$ & $28-42$ & 28 & 21 & 14 & 0.35 & 1.5 & $\mathrm{E} / \mathrm{B}$ & 10.40 & 9.79 & 0.94 \\
\hline $2 d-2 d$ & $28-56$ & 28 & 28 & 14 & 0.35 & 1.5 & $\mathrm{E} / \mathrm{B}$ & 9.22 & 9.79 & 1.06 \\
\hline $2 d-2.5 d$ & $28-80$ & 28 & 40 & 14 & 0.35 & 1.5 & $\mathrm{E} / \mathrm{B}$ & 8.31 & 9.79 & 1.18 \\
\hline $2 d-1 d$ & $28-28$ & 28 & 14 & 14 & 0.25 & 1.5 & $\mathrm{~N} / \mathrm{E}$ & 3.00 & 3.29 & 1.10 \\
\hline $2 d-1.5 d$ & $28-42$ & 28 & 21 & 14 & 0.25 & 1.5 & $\mathrm{E} / \mathrm{B}$ & 8.79 & 8.96 & 1.02 \\
\hline $2 d-2 d$ & $28-56$ & 28 & 28 & 14 & 0.25 & 1.5 & $\mathrm{E} / \mathrm{B}$ & 7.26 & 8.96 & 1.23 \\
\hline $2 d-2.5 d$ & $28-80$ & 28 & 40 & 14 & 0.25 & 1.5 & $\mathrm{E} / \mathrm{B}$ & 7.32 & 8.96 & 1.22 \\
\hline $3 d-1 d$ & $42-28$ & 42 & 14 & 14 & 0.35 & 1.5 & $\mathrm{~N} / \mathrm{B}$ & 3.94 & 4.64 & 1.18 \\
\hline $3 d-1.5 d$ & $42-42$ & 42 & 21 & 14 & 0.35 & 1.5 & $\mathrm{~N} / \mathrm{B}$ & 8.83 & 8.63 & 0.98 \\
\hline $3 d-2 d$ & $42-56$ & 42 & 28 & 14 & 0.35 & 1.5 & B & 8.07 & 10.60 & 1.31 \\
\hline $3 d-2.5 d$ & $42-80$ & 42 & 40 & 14 & 0.35 & 1.5 & B & 8.18 & 10.60 & 1.30 \\
\hline $4 d-1 d$ & $56-28$ & 56 & 14 & 14 & 0.35 & 1.5 & $\mathrm{~N} / \mathrm{B}$ & 3.96 & 4.64 & 1.17 \\
\hline $4 d-1.5 d$ & $56-42$ & 56 & 21 & 14 & 0.35 & 1.5 & $\mathrm{~N} / \mathrm{B}$ & 9.51 & 8.63 & 0.91 \\
\hline $4 d-2 d$ & $56-56$ & 56 & 28 & 14 & 0.35 & 1.5 & $\mathrm{~B}$ & 8.05 & 10.60 & 1.32 \\
\hline $4 d-2.5 d$ & $56-80$ & 56 & 40 & 14 & 0.35 & 1.5 & B & 7.66 & 10.60 & 1.38 \\
\hline $1 d-1 d$ & $\mathrm{~d} 10-10-20$ & 10 & 10 & 10 & 0.35 & 1.5 & $N / E$ & 3.83 & 3.97 & 1.04 \\
\hline $1 d-1.5 d$ & $\mathrm{~d} 10-10-30$ & 10 & 15 & 10 & 0.35 & 1.5 & $\mathrm{E}$ & 4.80 & 3.97 & 0.83 \\
\hline $1 d-2 d$ & $\mathrm{~d} 10-10-40$ & 10 & 20 & 10 & 0.35 & 1.5 & $\mathrm{E}$ & 4.35 & 3.97 & 0.91 \\
\hline $1 d-2.5 d$ & $\mathrm{~d} 10-10-50$ & 10 & 25 & 10 & 0.35 & 1.5 & $\mathrm{E}$ & 4.48 & 3.97 & 0.89 \\
\hline $2 d-1 d$ & $\mathrm{~d} 10-20-20$ & 20 & 10 & 10 & 0.35 & 1.5 & $\mathrm{~N} / \mathrm{E}$ & 3.18 & 3.26 & 1.03 \\
\hline $2 d-1.5 d$ & $\mathrm{~d} 10-20-30$ & 20 & 15 & 10 & 0.35 & 1.5 & $N / E$ & 8.14 & 6.99 & 0.86 \\
\hline $2 d-2 d$ & $\mathrm{~d} 10-20-40$ & 20 & 20 & 10 & 0.35 & 1.5 & E & 6.32 & 6.99 & 1.11 \\
\hline $2 d-2.5 d$ & $\mathrm{~d} 10-20-50$ & 20 & 25 & 10 & 0.35 & 1.5 & $\mathrm{E}$ & 5.42 & 6.99 & 1.29 \\
\hline $3 d-1 d$ & $\mathrm{~d} 10-30-20$ & 30 & 10 & 10 & 0.35 & 1.5 & $\mathrm{~N} / \mathrm{B}$ & 3.09 & 2.60 & 0.84 \\
\hline $3 d-1.5 d$ & $\mathrm{~d} 10-30-30$ & 30 & 15 & 10 & 0.35 & 1.5 & $\mathrm{~N} / \mathrm{B}$ & 5.35 & 5.07 & 0.95 \\
\hline $3 d-2 d$ & $\mathrm{~d} 10-30-40$ & 30 & 20 & 10 & 0.35 & 1.5 & $\mathrm{~B}$ & 4.78 & 6.30 & 1.32 \\
\hline $3 d-2.5 d$ & d $10-30-50$ & 30 & 25 & 10 & 0.35 & 1.5 & B & 4.48 & 6.30 & 1.41 \\
\hline $4 d-1 d$ & $\mathrm{~d} 10-40-20$ & 40 & 10 & 10 & 0.35 & 1.5 & $\mathrm{~N} / \mathrm{B}$ & 3.33 & 2.60 & 0.78 \\
\hline $4 d-1.5 d$ & $\mathrm{~d} 10-40-30$ & 40 & 15 & 10 & 0.35 & 1.5 & $\mathrm{~N} / \mathrm{B}$ & 5.89 & 5.07 & 0.86 \\
\hline $4 d-2 d$ & d $10-40-40$ & 40 & 20 & 10 & 0.35 & 1.5 & B & 4.70 & 6.30 & 1.34 \\
\hline $4 d-2.5 d$ & $\mathrm{~d} 10-40-50$ & 40 & 25 & 10 & 0.35 & 1.5 & B & 4.36 & 6.30 & 1.44 \\
\hline $1 d-1 d$ & $\mathrm{~d} 20-20-40$ & 20 & 20 & 20 & 0.35 & 1.5 & $\mathrm{~N} / \mathrm{E}$ & 9.54 & 7.93 & 0.83 \\
\hline $1 d-1.5 d$ & $\mathrm{~d} 20-20-60$ & 20 & 30 & 20 & 0.35 & 1.5 & $\mathrm{E}$ & 9.16 & 7.93 & 0.87 \\
\hline $1 d-2 d$ & $\mathrm{~d} 20-20-80$ & 20 & 40 & 20 & 0.35 & 1.5 & $\mathrm{E}$ & 7.98 & 7.93 & 0.99 \\
\hline $1 d-2.5 d$ & $\mathrm{~d} 20-20-100$ & 20 & 50 & 20 & 0.35 & 1.5 & $\mathrm{E}$ & 7.74 & 7.93 & 1.02 \\
\hline $2 d-1 d$ & $\mathrm{~d} 20-40-40$ & 40 & 20 & 20 & 0.35 & 1.5 & $\mathrm{~N} / \mathrm{E}$ & 5.08 & 6.52 & 1.28 \\
\hline $2 d-1.5 d$ & $\mathrm{~d} 20-40-60$ & 40 & 30 & 20 & 0.35 & 1.5 & $\mathrm{~N} / \mathrm{E}$ & 14.99 & 13.98 & 0.93 \\
\hline $2 d-2 d$ & d20-40-80 & 40 & 40 & 20 & 0.35 & 1.5 & $\mathrm{E}$ & 11.18 & 13.98 & 1.25 \\
\hline $2 d-2.5 d$ & d20-40-100 & 40 & 50 & 20 & 0.35 & 1.5 & $\mathrm{E}$ & 11.53 & 13.98 & 1.21 \\
\hline $3 d-1 d$ & d20-60-40 & 60 & 20 & 20 & 0.35 & 1.5 & $\mathrm{~N} / \mathrm{B}$ & 4.85 & 5.17 & 1.07 \\
\hline $3 d-1.5 d$ & $\mathrm{~d} 20-60-60$ & 60 & 30 & 20 & 0.35 & 1.5 & $\mathrm{~N} / \mathrm{B}$ & 13.73 & 10.14 & 0.74 \\
\hline $3 d-2 d$ & $\mathrm{~d} 20-60-80$ & 60 & 40 & 20 & 0.35 & 1.5 & $\mathrm{~B}$ & 10.15 & 12.60 & 1.24 \\
\hline $3 d-2.5 d$ & $\mathrm{~d} 20-60-100$ & 60 & 50 & 20 & 0.35 & 1.5 & B & 10.36 & 12.60 & 1.22 \\
\hline $4 d-1 d$ & $\mathrm{~d} 20-80-40$ & 80 & 20 & 20 & 0.35 & 1.5 & $\mathrm{~N} / \mathrm{B}$ & 5.04 & 5.17 & 1.03 \\
\hline $4 d-1.5 d$ & $\mathrm{~d} 20-80-60$ & 80 & 30 & 20 & 0.35 & 1.5 & $\mathrm{~N} / \mathrm{B}$ & 13.95 & 10.14 & 0.73 \\
\hline $4 d-2 d$ & $\mathrm{~d} 20-80-80$ & 80 & 40 & 20 & 0.35 & 1.5 & B & 10.17 & 12.60 & 1.24 \\
\hline $4 d-2.5 d$ & $\mathrm{~d} 20-80-100$ & 80 & 50 & 20 & 0.35 & 1.5 & B & 8.86 & 12.60 & 1.42 \\
\hline
\end{tabular}




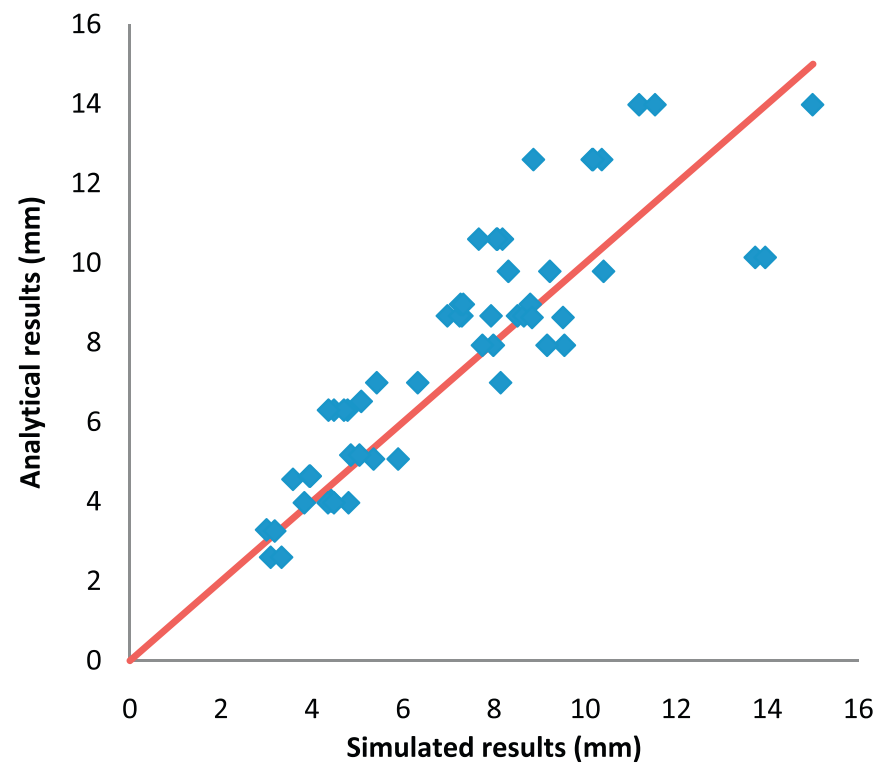

Fig. 18. Summary of comparison between ABAQUS simulation and analytical calculation results for bolt hole elongation.

between these two sets of results is very good, with an average difference of $17.4 \%$ and standard deviation of $11.5 \%$.

\subsection{Summary of calculation procedure}

To sum up, the procedure of calculating the bolt hole elongation at the maximum load is as follows:

\section{Tensile strain}

1. Determine the failure mode of the connection by comparing the end distance, the edge distance and the bolt hole diameter. The conditions are:

Net section failure mode

$e_{2}<\left(e_{1}+d\right) / 2$

$e_{2}<1.75 d \quad(10)$

End pull-out failure mode

$e_{1} \leq 2 e_{2}-d \quad(11)$

$e_{1} \leq 2.5 d \quad(12)$

Bearing failure mode

$e_{2} \geq 1.75 d \quad$ (13)

$e_{1} \geq 2.5 d \quad(14)$

2. Determine whether it is a pure failure mode or a mixed failure mode.

Mixed failure mode happens according to the following conditions.

Mixed net-section and end pull-out failure mode

$\left(e_{1}+0.5 d\right) / 2<e_{2}<\left(e_{1}+d\right) / 2$

Mixed net-section and bearing failure mode

$25 d<e_{2}<1.75 d$

Mixed end pull-out and bearing failure mode

$1.5 d<e_{1}<2.5 d$
2.1. If it is a pure failure mode, calculate the tensile strain values at the different critical points by referring to Figs. 11-13, respectively.

2.2. If it is a mixed failure mode, calculate the tensile strain values at the critical points by referring to Figs. 14-16, respectively.

\section{Compressive strain}

3. The maximum compression strain is 1.0 at $e_{1}=2 d$ and equals to the ultimate tensile strain of steel at $e_{1}=1.2 d$. Interpolate between these two values for other $e_{1}$ values.

4. Multiply the maximum compressive strain by a factor. This factor is 0 if $e_{2} \leq 0.75 d$. This factor is 1.0 if $e_{2} \geq\left(e_{1}+d\right) / 2$. Interpolate if $e_{2}$ is between these two limits.

5. Refer to Fig. 17 for the compression strain distribution in front of the bolt hole.

Bolt hole elongation

6. Calculate the total bolt hole elongation with contributions from the tensile elongation around the bolt hole circumference and the compressive pile up in front of the bolt.

\section{Conclusions}

This paper has presented a comprehensive experimental, numerical and analytical study of thin-walled plate behaviour under shear in a single bolt, emphasizing on bolt hole elongation. The following conclusions may be drawn:

(1) The experiments successfully revealed the three different anticipated failure modes: net section tension, end pull-out and bearing.

(2) The general finite element package ABAQUS was successfully applied to simulate these tests.

(3) Eurocode 3 and the Australian/New Zealand standard can be used to predict plate initial stiffness and strength.

(4) To predict the maximum bolt hole elongation, the tensile strain distribution around the bolt hole may be considered to be linearly distributed between five critical points. Compressive strain also exists in front of the bolt.

(5) This paper has proposed a method to calculate the strains at these critical points according to the aforementioned three failure modes and three mixed failure modes.

(6) Comparisons of the bolt hole elongation between ABAQUS simulation results and analytical calculations using the proposed strain distributions show that the proposed method gives very accurate results.

\section{Appendix. Calculation example}

End distance: $e_{1}=1.25 d$, edge distance: $e_{2}=1 d$, bolt hole diameter $d=14 \mathrm{~mm}$, plate thickness: $1.5 \mathrm{~mm}$, ultimate tensile stress of steel $=320 \mathrm{~N} / \mathrm{mm}^{2}$, Poisson's ratio $=0.3$ and ultimate tensile strain of steel $=0.35$.

Tensile strains

End pull-out load: $t e_{1} f_{u}=1.5 \times(1.25 \times 14) \times 320=8.4 \mathrm{kn}$

Net-section load: $t\left(2 e_{2}-d\right) f_{u}=1.5 \times(2-1) \times 14 \times 320=6.7 \mathrm{kn}$

Bearing failure load: $2.5 d t f_{u}=2.5 \times 14 \times 1.5 \times 320=16.8 \mathrm{kn}$

Therefore, the failure mode is net section failure.

Furthermore, since $\left(e_{1}+0.5 d\right) / 2<e_{2}<\left(e_{1}+d\right) / 2$, i.e. $0.875 d<$ $e_{2}<1.125 d$, the failure mode is mixed net-section/end pull-out.

For pure end pull-out failure mode (when $e_{2}=1.125 d$ ): 


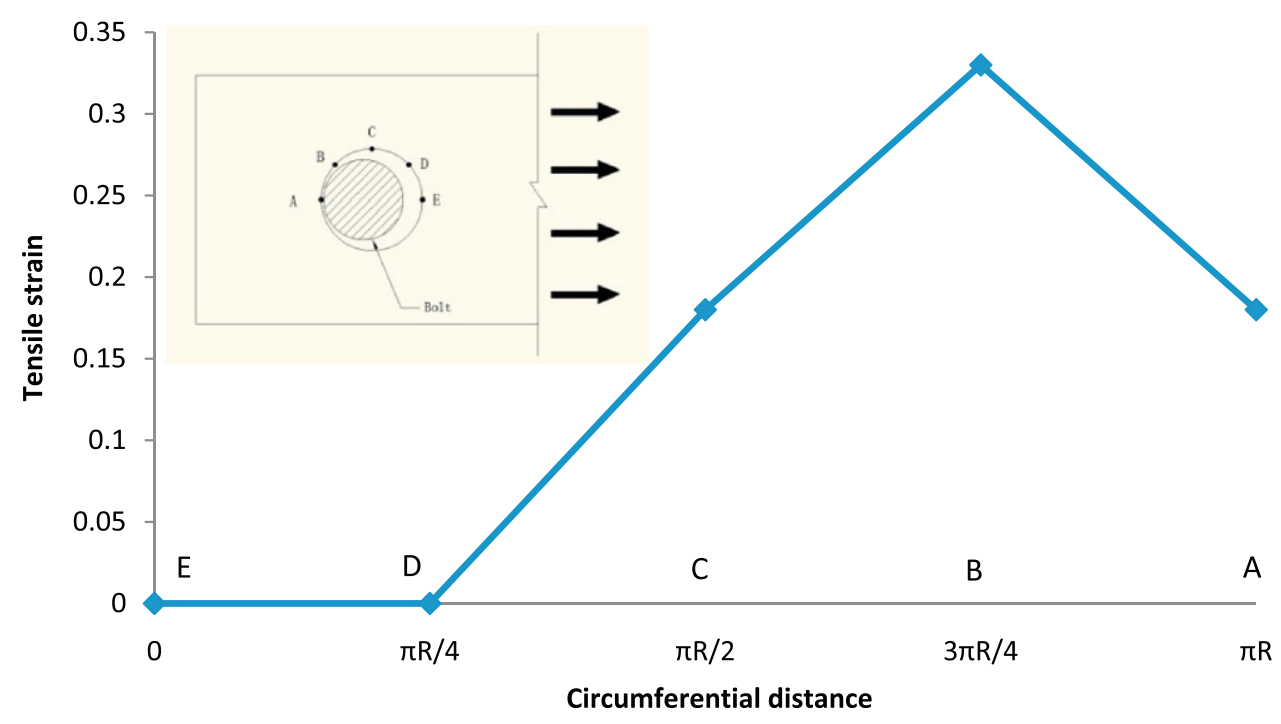

Fig. 19. Tensile strain distribution around bolt hole.

The tensile strains are

$\varepsilon_{A O}=0.35, \varepsilon_{B O}=0.65, \varepsilon_{C O}=0$

For pure net-section failure mode (when $e_{2}=0.875 d$ ):

The tensile strain are

$\varepsilon_{A O}=0, \varepsilon_{B O}=0, \varepsilon_{C O}=0.35$ $e_{2}=1 d$

Interpolation according to Fig. 14 for the tensile strains at

$\varepsilon_{C}=0.35-\frac{0.35-0}{1.125 d-0.875 d} \times(1 d-0.875 d)=0.18$

$\varepsilon_{B}=0+\frac{0.65-0}{1.125 d-0.875 d} \times(1 d-0.875 d)=0.33$

$\varepsilon_{A}=0+\frac{0.35-0}{1.125 d-0.875 d} \times(1 d-0.875 d)=0.18$

Fig. 19 shows the tensile strain distribution around the bolt hole.

The total bolt hole elongation due to tensile strain can be calculated as

$$
\begin{aligned}
D_{T} & =\frac{\pi R}{4} \varepsilon_{C}+\left(\varepsilon_{B}+\varepsilon_{C}\right) \frac{\pi R}{4} \frac{1}{2}+\left(\varepsilon_{A}+\varepsilon_{B}\right) \frac{\pi R}{4} \frac{1}{2} \\
& =5.5 \times 0.18+0.51 \times 2.75+0.51 \times 2.75 \\
& \Rightarrow D_{T}=3.80 \mathrm{~mm}
\end{aligned}
$$

\section{Compressive strain}

Since the failure mode is net-section, two linear interpolations are necessary.

First, calculate the maximum compressive strain.

At $e_{1}=1.2 d$, the maximum compressive strain is

$\varepsilon_{A C}=0.35$

At $e_{1}=2 d$, maximum compressive strain is $\varepsilon_{A C}=1.0$

Therefore, maximum compressive strain at $e_{1}=1.25 d$ is

$\varepsilon_{A C}=0.35+\frac{1-0.35}{2 d-1.2 d}(1.25 d-1.2 d)=0.39$

Second, find the multiplication factor for edge distance $e_{2}$ :

The lower bound is defined by

$e_{2}=0.75 d, \varepsilon_{A C}=0$

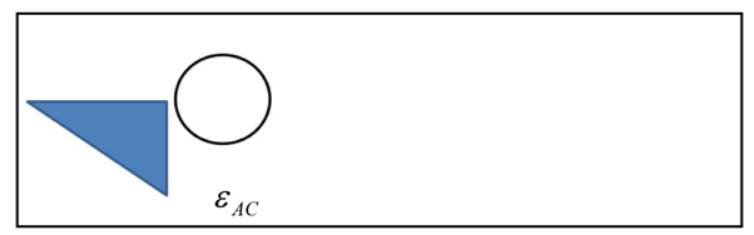

Fig. 20. Compressive strain distribution.

The upper bound is defined by

$e_{2}=(1.25 d+d) / 2=1.125 d, \quad \varepsilon_{A C}=0.39$

Interpolation for $e_{2}=1 d$

$\varepsilon_{A C}=0+\frac{0.39}{1.125 d-0.75 d}(1 d-0.75 d)=0.26$

Fig. 20 shows the compressive strain distribution along the plate length in front of the bolt.

The plate pile up due to compressive strain is

$D_{C}=\varepsilon_{A C} \frac{1}{2}(1.25 d-0.5 d)=0.26 \times \frac{1}{2} \times 0.75 \times 14=1.37 \mathrm{~mm}$

The total bolt hole elongation is

$D=D_{T}+D_{C}=3.80+1.37=5.17 \mathrm{~mm}$

\section{References}

[1] Cooke GME. Large sandwich panel fire resistance assessment. The Structural Engineer 2005:18-21.

[2] Wang YC, Davison JB, Burgess IW, Plank RJ, Yu HX, Dai XH, et al. The safety of common steel beam/column connections in fire. The Structural Engineer 2010:26-35.

[3] CEN. BS EN 1993-1-8, Eurocode 3: design of steel structures, part 1.8: design of joints, British Standards Institution; 2005.

[4] Rogers CA, Hancock GJ. Bolted connection tests of thin G550 and G300 sheet steels. Journal of Structural Engineering, ASCE 1998;124(7):798-808.

[5] Rex CO, Easterling WS. Behavior and modeling of a bolt bearing on a single plate. Journal of Structural Engineering 2003:792-800.

[6] Kim TS, Kuwamura H. Finite element modeling of bolted connections in thinwalled stainless steel plates under static shear. Thin-Walled Structures 2007;45(4):407-21.

[7] Hibbitt K, Sorensen S, Inc. ABAQUS/Standard, User’s Manual, I-III, version 6.3. Hibbit,Karlsson and Sorenson, Inc.; 2001. 
[8] CEN. BS EN 10002-1, Metallic materials-tensile testing, part 1: method of test at ambient temperature, Institution, British Standards; 2001.

[9] CEN. Eurocode 3. Design of steel structures, part 1.3 general rules, supplementary rules for cold formed thin gauge members and sheeting. Brussels, European Committee for Standardisation; 1996.

[10] CENEurocode 3. Design of steel structures, part 1.3 general rules, supplementary rules for cold-formed members and sheeting, British Standards Institution; 2006.
[11] Standards Australia, S. N. Z. Cold-formed steel structures-AS/NZS 4600. Sydney, NSW; 1996.

[12] American Iron and Steel Institute. 1996 Edition of the specification for the design of cold-formed steel structural members. Washington, DC; 1997.

[13] Rogers CA, Hancock GJ. Bolted connection design for sheet steels less than $1.0 \mathrm{~mm}$ thick. Journal of Constructional Steel Research 1999;51:123-46. 